\title{
Article \\ Biochemical, Ameliorative and Cytotoxic Effects of Newly Synthesized Curcumin Microemulsions: Evidence from In Vitro and In Vivo Studies
}

\author{
Abbas Rahdar ${ }^{1}\left(\mathbb{D}\right.$, Mohammad Reza Hajinezhad ${ }^{2}\left(\mathbb{D}\right.$, Saman Sargazi ${ }^{3, *}$, Maryam Zaboli $^{4}$, Mahmood Barani $^{5}{ }^{(D)}$, \\ Francesco Baino $^{6, *(\mathbb{D})}$, Muhammad Bilal ${ }^{7}$ (D) and Esmael Sanchooli ${ }^{8}$
}

Citation: Rahdar, A.; Hajinezhad, M.R.; Sargazi, S.; Zaboli, M.; Barani, M.; Baino, F.; Bilal, M.; Sanchooli, E. Biochemical, Ameliorative and Cytotoxic Effects of Newly Synthesized Curcumin

Microemulsions: Evidence from In Vitro and In Vivo Studies. Nanomaterials 2021, 11, 817. https:// doi.org/10.3390/nano11030817

Academic Editor: Constantine D. Stalikas

Received: 18 February 2021

Accepted: 19 March 2021

Published: 23 March 2021

Publisher's Note: MDPI stays neutral with regard to jurisdictional claims in published maps and institutional affiliations.
1 Department of Physics, University of Zabol, P.O. Box. 98613-35856, Zabol, Iran; a.rahdar@uoz.ac.ir

2 Basic Veterinary Science Department, Veterinary Faculty, University of Zabol, P.O. Box. 98613-35856, Zabol, Iran; hajinezhad@uoz.ac.ir

3 Cellular and Molecular Research Center, Resistant Tuberculosis Institute, Zahedan University of Medical Sciences, Zahedan 98167-43463, Iran

4 Department of Chemistry, University of Birjand, Birjand 97174-34765, Iran; Zaboli_maryam@yahoo.com

5 Department of Chemistry, Shahid Bahonar University of Kerman, Kerman 76169-14111, Iran; mahmoodbarani7@gmail.com

6 Institute of Materials Physics and Engineering, Applied Science and Technology Department, Politecnico di Torino, Corso Duca degli Abruzzi 24, 10129 Torino, Italy

7 School of Life Science and Food Engineering, Huaiyin Institute of Technology, Huaian 223003, China; bilaluaf@hotmail.com

8 Department of Chemistry, University of Zabol, P.O. Box. 98613-35856, Zabol, Iran; esmael.sanchooli@uoz.ac.ir

* Correspondence: sgz.biomed@gmail.com (S.S.); francesco.baino@polito.it (F.B.)

Abstract: Curcumin is known to exhibit antioxidant and tissue-healing properties and has recently attracted the attention of the biomedical community for potential use in advanced therapies. This work reports the formulation and characterization of oil-in-water F127 microemulsions to enhance the bioavailability of curcumin Microemulsions showed a high encapsulation efficiency and prolonged release. To investigate the interactions of curcumin with one unit of the polymeric chain of surfactant F127, ethyl butyrate, and sodium octanoate, as well as the interaction between ethyl butyrate and one unit of the F127 polymer chain, the Density Functional Theory (DFT) calculations at the M06-2X level of theory, were performed in water solution. The MTT assay was used to assess the cytotoxicity of free and encapsulated curcumin on non-malignant and malignant cell lines. Combination effects were calculated according to Chou-Talalay's principles. Results of in vitro studies indicated that MCF7 and HepG2 cells were more sensitive to curcumin microemulsions. Moreover, a synergistic relationship was observed between curcumin microemulsions and cisplatin in all affected fractions of MCF7 and HepG2 cells ( $\mathrm{CI}<0.9)$. For in vivo investigation, thioacetamide-intoxicated rats received thioacetamide (100 mg/ kg Sc) followed by curcumin microemulsions (30 mg/kg Ip). Thioacetamideintoxicated rats showed elevated serum liver enzymes, blood urea nitrogen (BUN), and creatinine levels, and a significant reduction in liver superoxide dismutase (SOD) and catalase (CAT) activities $(p<0.05)$. Curcumin microemulsions reduced liver enzymes and serum creatinine and increased the activity of antioxidant enzymes in thioacetamide-treated rats in comparison to the untreated thioacetamide-intoxicated group. Histopathological investigations confirmed the biochemical findings. Overall, the current results showed the desirable hepatoprotective, nephroprotective, and anti-cancer effects of curcumin microemulsions.

Keywords: biomaterials; nanocarrier; oil-in-water F127 microemulsions; curcumin; hepatoprotective; antioxidant; nephrotoxicity

\section{Introduction}

Curcumin, obtained from Curcuma longa rhizomes, has displayed a wide range of immunomodulatory, antioxidant, and anti-inflammatory activities. Early reports have re- 
vealed the promising protecting effects of curcumin against oxidative stress-mediated renal dysfunction, liver injury, cardiotoxicity, neuropathy, and immune dysfunction [1]. However, several physicochemical disadvantages limit the therapeutic efficacy of curcumin, including its chemical instability, photo-degradation, fast precipitation in water-based solvents, short half-life, and rapid metabolism, leading to poor bioavailability. Previous reports have shown that new nano-delivery systems provide effective solutions for overcoming the pharmaceutical drawbacks of curcumin, leading to significant therapeutic efficacy enhancement [2-8].

Curcumin was reported to enhance the sensitivity of resistant MCF-7 cells to conventional anti-cancer agents. As a yellow pigment from turmeric, the phenolic content of curcumin triggers apoptotic cell death through mitochondrial hyperpolarization in human hepatoma cells [9]. It has been widely utilized in blending with alkylating agents to enhance the anti-cancer efficacy against different tumor cells [10,11].

Nowadays, nanotechnology is emerging as an exciting field that finds broad-spectrum applications in nutrition, cosmetics, and biomedical products to improve the bioavailability of therapeutic molecules or drugs [3,4,6,8,12-23]. In contrast to larger-scale counterparts, nanoscale materials often display more appealing physical and chemical attributes as well as attractive biological potentialities [19,24-29]. The bioavailability could be markedly enhanced by the increased dissolution rate because of the reduced particle size of the active pharmaceutical constituent [30]. Therefore, this approach might be considered a practical solution to enhance the bioavailability and solubility of poorly soluble drug molecules.

Among the various colloidal systems with potential solubilizing applications for hydrophobic compounds, oil-in-water emulsions represent one of the most technicallyappealing alternatives for such purposes [31]. Emulsions are categorized into microemulsions, nanoemulsions, and macroemulsions. As anticipated from their names, this classification is based on the size of the dispersed phase particles. Still, the significant difference among these types of emulsions is thermodynamic stability [32]. Microemulsions are recognized to be the preferred candidates in the development of solubilization platforms owing to their high thermodynamic stability and the requirement of minimum mechanical energy for their fabrication. Furthermore, their substantial specific surface area makes them suitable vehicles for promoting the availability of solubilized substances [33,34].

Several reports have demonstrated the potential utilization of microemulsions as a delivery platform to improve the therapeutic action of targeted molecules, thus diminishing the toxicity of the drug to humans [13,15,17,23,35-46]. Dhumal et al. [47] developed a new self-micro-emulsifying drug delivery system (SMEDDS) by using oleic acid (semisynthetic)-originated bicephalous heterolipid (E1E) for enhancing the bioavailability and solubility of curcumin. The curcumin solubility in E1E was 2.6- and 14-folds increased compared to using ethyl oleate and oleic acid, respectively. The E1E-based SMEDDS showed an excellent curcumin encapsulation efficacy of $70.52 \mathrm{mg} \mathrm{g}^{-1}$ and formed a spontaneous microemulsion by inclusion into aqueous phase with a polydispersity index and average globule size of 0.243 and $22.39 \mathrm{~nm}$, respectively. After the delivery via E1E-based SMEDDS, the absorptive ability of curcumin was improved to 26 folds. A freeze-drying method was used to prepare novel curcumin-loaded hydroxypropylmethylcellulose (HPMC)-based sponge formulations with a mean pore size ranging from 43.36 to $123.22 \mathrm{~nm}$. The optimal sponge formulation gave rise to an average microemulsion diameter of $34.80 \mathrm{~nm}$, leading to a complete release of curcumin within $2 \mathrm{~h}$. After oral administration of curcumin-loaded sponges in rabbits, the area under the concentration-time curve (AUC) was 5- to 7-folds increased as compared with the normal curcumin powder [48]. In order to determine the potential protective effects of curcumin microemulsions against the hepatotoxicant thioacetamide, rats received three injections of thioacetamide. Thioacetamide administration is an excellent model to induce sub-acute renal and hepatic injury and oxidative stress in laboratory animals. It is worth noting that the concentration of oil, drug, surfactants, and co-surfactants might influence the stability of drug/biomolecule-encapsulating oil-in-water microemulsion systems. Given their low toxicity and great stability, Pluronics have gained 
importance as preferred non-ionic surfactants in designing oil-in-water microemulsions for pharmaceutical purposes rather than ionic surfactants [49-53]. Our research group recently developed Pluronic F127-based biodegradable and biocompatible microemulsions to increase the solubility and delivery of tocopherol. Besides the high encapsulation capacity, the as-formulated micro emulsion-based nanocarriers presented a sustained release profile of the cargo [39]. Nevertheless, no report has been conducted so far on preparing oil-in-water F127 microemulsions to augment the bioavailability of curcumin. The effect of intraperitoneal injections of curcumin microemulsions on thioacetamide-induced oxidative stress has also not been examined yet. Therefore, this study investigates the nanoformulation and characterization of such oil-in-water Pluronic F127 microemulsions. The biochemical, ameliorative, and cytotoxic effects of curcumin microemulsions were specifically evaluated to provide evidence for in vitro and in vivo application of this novel formulation.

\section{Materials and Methods}

\subsection{Materials}

Standard laboratory grade chemicals, including curcumin, sodium octanoate (commonly called sodium caprylate), and ethyl butyrate were provided by Sigma Chemical Co. (Taufkirchen, Germany). Pluronic surfactant F127 was procured from BASF Inc. (Mount Olive, NJ, USA) DMSO, 3-(4,5-dimethylthiazol-2-yl)-2,5-diphenyl-tetrazolium bromide (MTT), and cisplatin were procured from Sigma-Aldrich Chemical Company (St Louis, MO, USA). Fetal bovine serum (FBS) was procured from Biochrome (Berlin, Germany). Culture mediums, including Dulbecco's Modified Eagle's medium (DMEM) and RPMI, and also antibiotic/antimycotic solution were supplied by INOCLON (G. Innovative Biotech Co, Tehran, Iran). Plastic materials were obtained from SPL life Science (SPL, Seoul, Korea). All other chemicals/reagents were of a high quality and used as such.

\subsection{Formulation of Curcumin-Incorporated Microemulsions}

The synthesis of curcumin-incorporated oil-in-water microemulsions [54] involved the vigorous stirring of a suitable amount of sodium caprylate, F127, PBS ( $\mathrm{pH}=7.4$ ) at a fixed curcumin-to-Pluronic molar ratio of 0.043 . Scheme 1 portrays the schematic representation of the newly synthesized Pluronic microemulsion structure and contents.
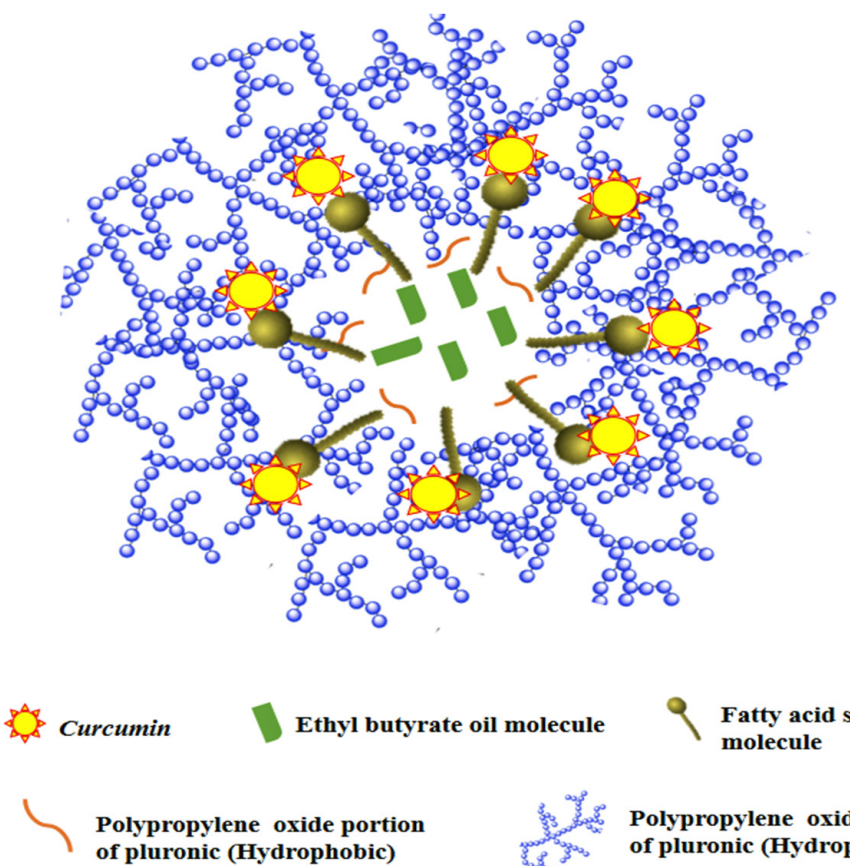

of pluronic (Hydrophobic)

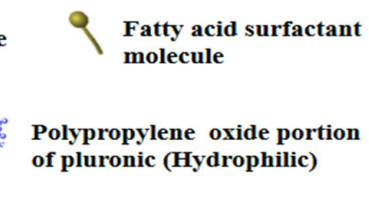

Scheme 1. Computational study. 


\subsection{Computational Study}

The geometry of monomers and the obtained complexes were optimized by using DFT at M06-2X [55] functional level. The M06-2X functional is able to perform both electrostatic and dispersion interactions. All calculations were performed by applying the standard 6-31G* basis set within the Gaussian 03 program package [56]. The solvation (water) effect was calculated by using the polarizable continuum model (PCM) of the selfconsistent reaction field (SCRF) $[57,58]$. The interaction energy $\left(E_{\text {int }}\right)$ values were obtained by subtracting the energies of the isolated monomers from the energy of the complex:

$$
\mathrm{E}_{\text {int }}=\mathrm{E}_{\text {complex }}-\mathrm{E}_{\text {monomer }_{1}}-\mathrm{E}_{\text {monomer }_{2}}+\mathrm{E}_{\mathrm{BSSE}}
$$

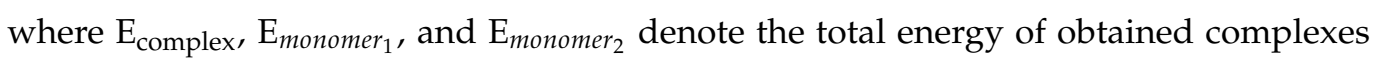
after interaction of two monomers and the total energies of the optimized monomers, respectively. The $\mathrm{E}_{\mathrm{BSSE}}$ value shows the basis set superposition error (BSSE) that was obtained by applying the counterpoise procedure of Boys and Bernardi according to the below Equation [59]:

$$
\begin{aligned}
\mathrm{E}_{\mathrm{BSSE}}=\mathrm{E}\left(\text { monomer }_{1}{ }^{\prime}\right)_{\text {monomer }_{1}} \pm \mathrm{E}\left(\text { monomer }_{1}{ }^{\prime}\right)_{\text {complex }} \\
+\mathrm{E}\left(\text { monomer }_{2}\right)_{\text {monomer }_{2}} \pm \mathrm{E}\left(\text { monomer }_{2}{ }^{\prime}\right)_{\text {complex }}
\end{aligned}
$$

where $E\left(\text { monomer }_{1}{ }^{\prime}\right)_{\text {complex }}$ shows the energy calculated for monomer $r_{1}$ with its geometry in the complex and the complete set of basic functions applied to describe the dimer. Moreover, $\mathrm{E}\left(\text { monomer }_{1}{ }^{\prime}\right)_{\text {monomer }}$ is the energy structure of monomer $_{1}$ on the complex calculated by using its corresponding basis set [60]. The Atoms in Molecules (AIM) method was used to analyze the topological parameters related to the intermolecular hydrogen bond (H-bond) formation [61,62]. The AIM analysis was carried out by using the AIM2000 program [63] at the M06-2X/6-31G* level of theory. The natural bond orbital (NBO) method $[64,65]$ was used to analyze the natural population and the charge transfer during the reaction course.

\subsection{Characterization of Curcumin-Loaded Microemulsions by Dynamic Light Scattering (DLS)}

DLS characterization of curcumin-incorporated microemulsions was carried out by using an ALV-5000F Goniometer System coupled with a diode-pumped solid-state laser to supply polarized incident light. This technique is commonly used to assess the size of nanomaterials and nano-systems [66-69]. The measurement equipment was also integrated with a digital correlator (ALV SP-86) with a sample range of $25 \mathrm{~ns}$ to $100 \mathrm{~ms}$. DLS was performed at an angle of $\theta=90^{\circ}$ to the incident ray by calibrating the intensity scale by toluene against scattering. Before measuring, the sample solutions were directly filtered into scattering cells using Millipore Millex filters $(0.22 \mu \mathrm{m}$ porosity) and equilibrated for $10 \mathrm{~min}$ at the required temperature. In order to acquire a fitted correlation function, the sampling time was 5-10 min. All the experiments were carried out three times.

\subsection{Entrapment Efficiency of Curcumin}

In order to calculate the content of curcumin in the formulations, the UV-spectrophotometric approach was used (Agilent Technologies, Cary 50, Santa Clara, California, USA) $[8,17,23]$. Curcumin stock solution $(30 \mu \mathrm{g} / \mathrm{mL})$ was diluted with ethanol/PBS 7.4 (1:1) from the curcumin commercial product. At wavelengths of 200 to $700 \mathrm{~nm}$, the absorbance peak of curcumin was initially determined. The curcumin showed a characteristic peak at a wavelength of $420 \mathrm{~nm}$. For calibration curves, working standard solutions of curcumin were prepared by diluting the stock solution within a concentration range of $30-0.25 \mu \mathrm{g} / \mathrm{mL}$, and spectrophotometric determination was carried out at $420 \mathrm{~nm}$. The curve $\left(R^{2}=0.9895\right)$ was found to be linear and reproducible. Curcumin-containing microemulsions were then centrifuged at 20,000 rpm for $60 \mathrm{~min}$ (model MC-20000, Medline, UK). The curcumin content of the resulting supernatant solution was calculated by absorbance measurement at $420 \mathrm{~nm}$. Eventually, the encapsulation efficiency (EE percent) was determined as the differ- 
ence between the total microemulsion curcumin $(\mathrm{Crcm})$ content and the free supernatant curcumin according to Equation (3):

$$
E E(\%)=\frac{(\text { Total } \mathrm{Crcm}-\text { Free } \mathrm{Crcm})}{\text { Total } \mathrm{Crcm}} \times 100
$$

\subsection{Release Study}

Release activity was tested using a dialysis technique with a 6000 Da pore size dialysis membrane $[4,8,17]$. For at least $12 \mathrm{~h}$ prior to use, the dialysis bag was immersed in the PBS buffer as a receptor. As a donor portion, $1 \mathrm{~mL}$ of curcumin solution or curcuminloaded microemulsion was placed in the dialysis bag. In the receiver chamber, $50 \mathrm{~mL}$ PBS 7.4/ethanol was added. Curcumin release tests were conducted over $24 \mathrm{~h}$ at $37{ }^{\circ} \mathrm{C}$ and a speed of $90 \mathrm{rpm} ; 1 \mathrm{~mL}$ of the buffer medium as the receiver was collected at various time intervals, and subsequently, the same quantity of fresh buffer (preheated at $37^{\circ} \mathrm{C}$ before replacement) was added to a receiver to maintain a steady volume. The UV spectrophotometer measured the absorbance of the samples at a $420 \mathrm{~nm}$ wavelength. The released curcumin was withdrawn and analyzed in a quartz cuvette with an area of $1 \times 1 \mathrm{~cm}^{2}$ by using a UV-Vis spectrophotometer (Agilent Technologies, Cary 100, Santa Clara, CA, USA). Each experiment was measured in triplicate.

By fitting the release results to a zero-order, first-order, Higuchi and Korsmeyer-Peppas models, the release kinetics of curcumin were predicted [8]. The profile of percent release vs. time for the zero-order, the profile of log of percent release vs. time for the first-order, the profile of the percent release vs. the square root of time for the Higuchi model, and the profile of log of percent release vs. log of time for Korsmeyer-Peppas model was plotted.

\subsection{In Vitro Studies}

\subsubsection{Cell Lines and Cultivation Conditions}

Human umbilical vein endothelial cells (HUVECs) were a kind gift from Dr. Roghayeh Sheervalilou. HUVECs were cultured in DMEM medium. HEK293 cells, as another nonmalignant cell lines derived from the human embryonic kidney, were procured from the cell collection of Royan Institute (Tehran, Iran) and grown in high-glucose DMEM. MCF-7 human breast cancer and HepG2 human hepatoma cell lines were procured from the Cell Repository of the Research Institute of Biotechnology, Ferdowsi University of Mashhad, Iran, and were cultivated in RPMI-1640 culture media. Both cell lines tested negative for mycoplasma contamination. For cultivation of all cell lines, the culture medium was supplemented with $10 \%$ heat-activated FBS, penicillin $(950 \mathrm{U} / \mathrm{mL})$, amphotericin B $(250 \mu \mathrm{g} / \mathrm{mL})$, and streptomycin $(50 \mu \mathrm{g} / \mathrm{mL})$, and was maintained at standard cell culture conditions [70].

\subsubsection{MTT Cytotoxic Assay}

Cytotoxicity exerted by free curcumin and curcumin-loaded microemulsions on cell lines was investigated by performing the MTT assay [71]. Cells $\left(5 \times 10^{3}\right.$ cells/well) were seeded in 96-well microplate in triplicates, incubated overnight, and treated with free curcumin and curcumin-loaded microemulsions from 0 to $300 \mu \mathrm{g} / \mathrm{mL}$. Cisplatin was added in the range of 0 to $32 \mu \mathrm{g} / \mathrm{mL}$ concentrations for comparing its cytotoxic activity with free and encapsulated curcumin. After incubation for $48 \mathrm{~h}, 20 \mu \mathrm{L}$ of MTT reagent $(5 \mathrm{mg} / \mathrm{mL})$ was included in each well following incubation at $37^{\circ} \mathrm{C}$ for $4 \mathrm{~h}$. Next, the culture medium was cautiously removed and replaced with the addition of $200 \mu \mathrm{L}$ of DMSO for complete solubilization of formazan crystals. The absorbance was read at $570 \mathrm{~nm}$ by using a Gemini microtiter plate reader. The viable cells percentage was assessed as the ratio of sample OD to the control OD. The results represent the mean \pm SD of three independent experiments. GraphPad Prism software version 7.0 was used to measure the half-maximal inhibitory concentration $\left(\mathrm{IC}_{50}\right)$ as $\mu \mathrm{g} / \mathrm{mL}$. 


\subsubsection{Analysis of Combined Drug Effects}

Analysis of drug interactions was performed by using Chou and Talalay's methods [72]. For this purpose, HepG2 and MCF7 cells were simultaneously treated with free or encapsulated curcumin and cisplatin as a single agent in fixed-ratio combinations. Increasing concentrations, each diluted 1:2 within the acceptable ranges, were used. For each level of fraction affected $(\mathrm{Fa})$, the combination index (CI) for indicating drug interactions was calculated via CompuSyn software (Version 1.0), where CI $<1, \mathrm{CI}=1$, and CI $>1$ represents synergism, additivity, and antagonism, respectively.

\subsection{Animal Treatments and Grouping Design}

The experimental works on laboratory animals were conducted in the laboratory animal center of the University of Zabol, Zabol, Iran. In the current work, thirty-two male adult white rats (mean weight $223 \mathrm{~g}$ ) were housed in poly (carbonate) cages. The laboratory animal house which the animals held had $25^{\circ} \mathrm{C}$ with a $12 \mathrm{~h} \mathrm{light} / 12 \mathrm{~h}$ dark program. Animals had free access to standard rodent chow pellets (manufactured by Javaneh-Khorasan company, Mashhad, Iran) and sterile tap water. In order to acclimatize the rats for the experimental procedure, animals were kept at a two-week adaptation period before the experiments. The experimental methods and rat handling were performed according to the international ethical procedures for the use and care of laboratory rodents (from NIH Publication No.85-23). The experimental procedure was performed according to guidelines of the ethical research committee of the University of Zabol, Zabol, Iran (IR.UOZ.REC.1399).

Animals were allocated randomly into four groups, as follows. The healthy control rats received $0.5 \mathrm{~mL}$ intraperitoneal injection of saline for 28 days. The rats of the second group were daily treated with intraperitoneal injections of curcumin microemulsions at a dose of $30 \mathrm{mg} / \mathrm{kg}$ for 28 days. The dose of curcumin microemulsions was selected according to previous reports [73] and our preliminary experiments.

The third group was treated by three consecutive subcutaneous injections of thioacetamide $(100 \mathrm{mg} / \mathrm{kg})$ for four weeks. The fourth group received three successive subcutaneous injections of thioacetamide $(100 \mathrm{mg} / \mathrm{kg})$ at $24 \mathrm{~h}$ intervals following $30 \mathrm{mg} / \mathrm{kg}$ curcumin microemulsions for four weeks. The doses of thioacetamide were selected based on previous studies and preliminary experiments [74]. After four weeks of treatments, blood samples were collected by the retro-orbital sinus puncture method. The obtained blood samples were immediately sent to the clinical pathology laboratory of the University of Zabol for determining biochemical parameters. After immediate centrifugation of blood samples (3000 rpm for $5 \mathrm{~min}$ ), the obtained serum samples were separated from blood and preserved at $-20^{\circ} \mathrm{C}$.

\subsection{Serum Biochemical analysis}

Serum ALT, AST, blood urea nitrogen (BUN), and creatinine were determined by using Pars Azmoon kits (Tehran, Iran), according to the manufacturer's instructions. Analysis of biochemical parameters was done by Selectra Pro M autoanalyzer. Serum malondialdehyde content was measured by adopting the method described by Ohkawa et al., with minor modifications [75]. Serum catalase activities were determined by using the Goth method [76]. Furthermore, the SOD activity was measured by the Sun method with minor changes [77].

\subsection{Statistical Analysis}

Serum biochemical parameters were studied by one-way ANOVA followed by Tukey's post-hoc test. The biochemical results were examined using the SPSS software (version 20.0), where significant differences among the groups were set at $p<0.05$. 


\section{Results and Discussion}

\subsection{Synthesis and Characterization of Curcumin-Loaded Microemulsions}

Figure 1a shows a scheme of size distribution for as-prepared microemulsions. The size of curcumin-based microemulsions measured to be approximately $8 \mathrm{~nm}$.

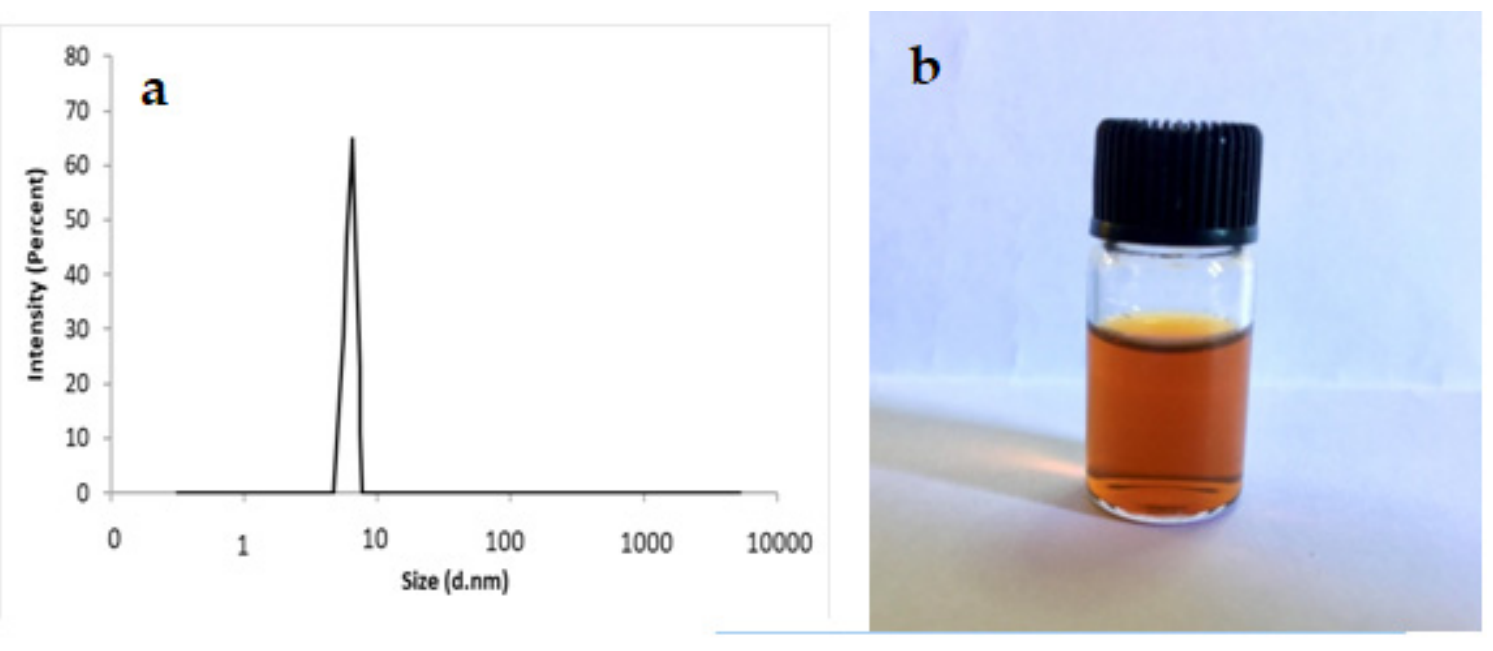

Figure 1. DLS results: (a) size distribution; (b) visual stability of microemulsion after six months.

Regarding stability of microemulsions, the PDI obtained from DLS analysis of microemulsions showed values (0.1-0.2), indicating a size homogeneity of the droplets in the total microemulsion. The stability of the microemulsion was confirmed visually after six months of preparation and no aggregation was observed (Figure 1b).

\subsection{Quantum Mechanics Calculations}

The interactions of curcumin with one unit of the polymeric chain of surfactant F127, ethyl butyrate, and sodium octanoate were studied; furthermore, the interaction between ethyl butyrate with one unit of F127 polymer chain was investigated in water solution as well. The obtained complexes have been introduced with CURF, CUREthyl, CURSodium, and EthylF, respectively. The geometry optimization of monomers and the obtained complexes was done at the M06-2X level of theory. The optimized structure of monomers and the resulting complexes are shown in Figures S1 and S2 in the supplemental material. All possible positions for interaction between the mentioned monomers were considered and indicated in Figure S2.

Moreover, the adsorption energy values are indicated in Figure S2, which shows that the most stable complexes belong to the interaction between curcumin and F127, i.e., CURF1 and CURF2 complexes.

\subsubsection{AIM Analysis}

The topological properties of electron densities are generally interpreted according to the quantum theory of atoms in molecules. AIM theory is a convenient method in quantum mechanics to examine various interactions [78]. Topological parameters are often used to detect the presence of hydrogen bond interactions and are also applied as descriptors to describe the H-bond strength $[79,80]$. The electron density, Laplacian of electron density, and total energy density values $\left(\varrho(\mathrm{r}), \nabla^{2} \varrho(\mathrm{r}), \mathrm{H}(\mathrm{r})\right.$, respectively) at the bond critical points (BCPs) of all complexes are indicated in Table S1. The results of NBO analysis are reported in Table S2.

The molecular graph of one of the most stable complexes is displayed in Figure S3, which demonstrates distinctly the bond critical point (red balls), ring critical point (yellow balls), and the bond paths. 
The Espinosa method was applied as a powerful technique for estimating H-bond energy [81]. In this method, the individual hydrogen bond energies $\left(E_{H B}^{*}\right)$ were estimated using the electron densities at the hydrogen bond critical points. The maximum electron density and $E_{H B}^{*}$ values at the $\mathrm{H}$-bond critical points belong to CURF2 and CURSodium3 complexes at the $\mathrm{H}_{47}-\mathrm{O}_{54}, \mathrm{H}_{66}-\mathrm{O}_{9}$ bonds, respectively (see Table $\mathrm{S} 1$ ). There is a good correlation between the $E_{H B}^{*}$ values and the geometrical parameters. Therefore, it can be concluded that the geometrical parameters are good descriptors to show the $\mathrm{H}$-bond strength. It is determined that the shorter the $\mathrm{H} \cdots \mathrm{Y}$ (Y is the proton acceptor), the stronger the $\mathrm{H}$-bond. Therefore, it is reasonable that the $\mathrm{H}_{47}-\mathrm{O}_{54}$ in the CURF2 complex and the $\mathrm{H}_{66}-\mathrm{O}_{9}$ bond in the CURSodium3 complex have a minimum bond length (see Figure S4).

The positive $\nabla^{2} \varrho(\mathrm{r})$ and $\mathrm{H}(\mathrm{r})$ values at the contact points indicate the weak H-bonds between the studied monomers except for $\mathrm{H}_{47}-\mathrm{O}_{54}$ contact of CURF2 complex and $\mathrm{H}_{66}-\mathrm{O}_{9}$ bond in CURSodium 3 , since $\nabla^{2} \varrho(\mathrm{r})>0$ and $\mathrm{H}(\mathrm{r})<0$ show medium-strength intermolecular interaction with partially covalent nature in these points. The $\varrho(r)$ at BCP of X $\cdots H$ contact are well correlated with the $E_{H B}^{*}$ value; consequently, a higher value of $\varrho(\mathrm{r})$ corresponds to stronger $\mathrm{H}$-bond interactions. The correlation between $\nabla^{2} \varrho(\mathrm{r})$ and $E_{H B}^{*}$ at intermolecular interaction is demonstrated in Figure S5.

\subsubsection{HOMO-LUMO Analyses}

The LUMO indicates the ability to acquire an electron and act as an electron acceptor, while the HOMO shows the ability to donate an electron. The energy gap $\left(\mathrm{E}_{\mathrm{g}}\right)$ and the HOMO and LUMO orbitals for the most stable complex (CURF2) are shown in Figure S6.

The HOMO and LUMO energy values of monomers were applied to calculate the

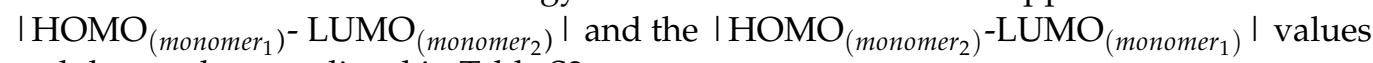
and the results were listed in Table S3.

\subsubsection{Thermodynamic Parameters}

The thermodynamic parameters of all complexes, including Gibbs free energy $(\Delta \mathrm{G})$, enthalpy $(\Delta \mathrm{H})$, and entropy $(\Delta \mathrm{S})$ were calculated at the standard situation (STP, $1 \mathrm{~atm}$, and $298 \mathrm{~K})$. The obtained results are listed in Table S4.

\subsection{Entrapment Efficiency}

One of the significant physiochemical properties in the design of drug nanostructures is encapsulation efficiency (EE) $[5,8,12,82]$. High EE guarantees treatment efficacy provided by loaded substances at a lower dose than that needed for free chemical molecules to be administered, thus minimizing the level of adverse side effects [3-5]. The curcumin microemulsion encapsulating performance was $88 \pm 1.5 \%$. Sharma et al. reported an EE of $69.98 \pm 0.21$ to $83.32 \pm 0.15 \%$ for curcumin-loaded Pluronic F-127 microemulsions [83] Chen et al. prepared curcuminoid microemulsions consisting of soybean oil, Tween 80 , ethanol, and water with an EE of 85.7\% [84]. Based on this study, this high EE percentage may be due to interactions between curcumin and microemulsions, which can result in a more rigid microemulsion membrane and affect curcumin release. Furthermore, the microemulsion core is hydrophobic, and it can be said that curcumin is mainly encapsulated in the core of the microemulsion.

\subsection{In Vitro Release Experiment}

The curcumin solution and curcumin-loaded microemulsion in vitro release experiments were performed using dialysis methods at PBS 7.4/ethanol $(1: 1)$ and $37^{\circ} \mathrm{C}$. The free curcumin $(\mathrm{Crcm})$ release rate was significantly faster (like a burst-release behavior) than the curcumin-loaded microemulsion, as shown in Figure 2. Curcumin release reached only $52 \%$ after $24 \mathrm{~h}$ for curcumin-loaded microemulsion, which showed a slow release rate. This is a significant achievement potentially enabling a prolonged therapeutic effect. In a previous study, Sharma et al. reported that curcumin release of about $74 \%$ in $8 \mathrm{~h}$ for optimized microemulsion formulations [83]. 


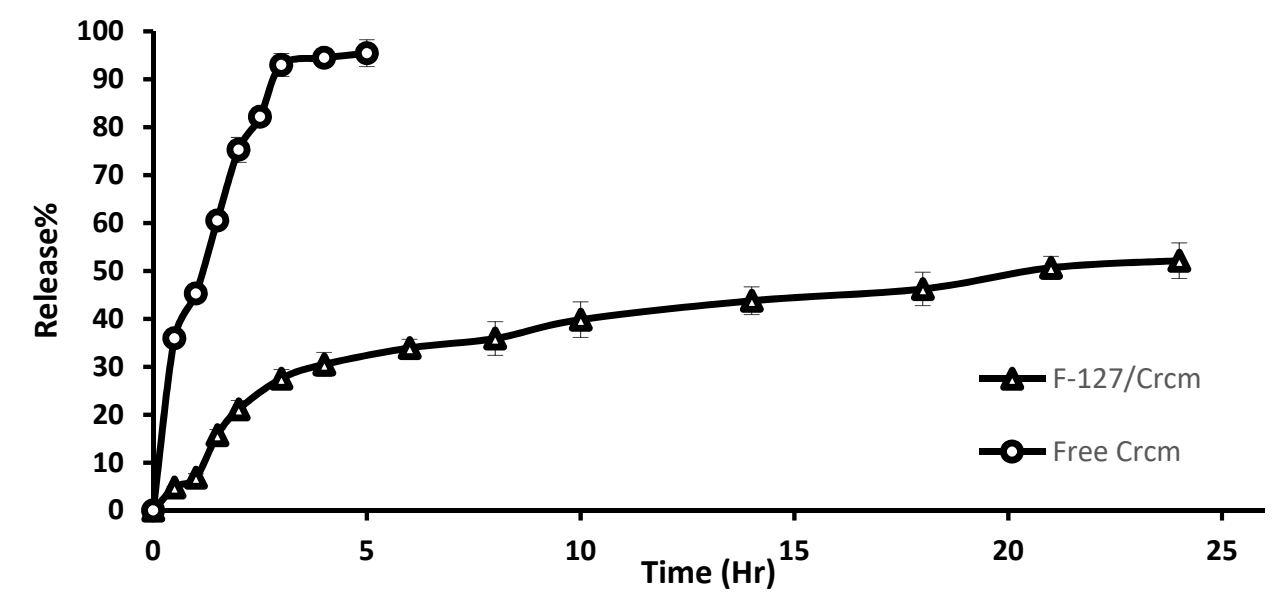

Figure 2. In vitro release of free curcumin (Crcm) and curcumin-loaded microemulsion (F-127/Crcm) at PBS 7.4/ethanol $(1: 1)$ and $37^{\circ} \mathrm{C}$ after $24 \mathrm{~h}$.

By matching the first-order, zero-order, Higuchi, and Korsmeyer-Peppas models, curcumin release kinetics were evaluated. As shown in Figure 3, the Higuchi model was better suited to the microemulsion curcumin release rate $\left(R^{2}=0.9271\right)$. This kind of release describes the drug release as a diffusion process based on Fick's law, which is square root time-dependent. At the beginning of the process and in the presence of water, the microemulsion may gradually expand, allowing the loaded drug to spread through the membrane. The lipophilic fatty cores, however, will decrease the diffusion coefficient of curcumin [8].
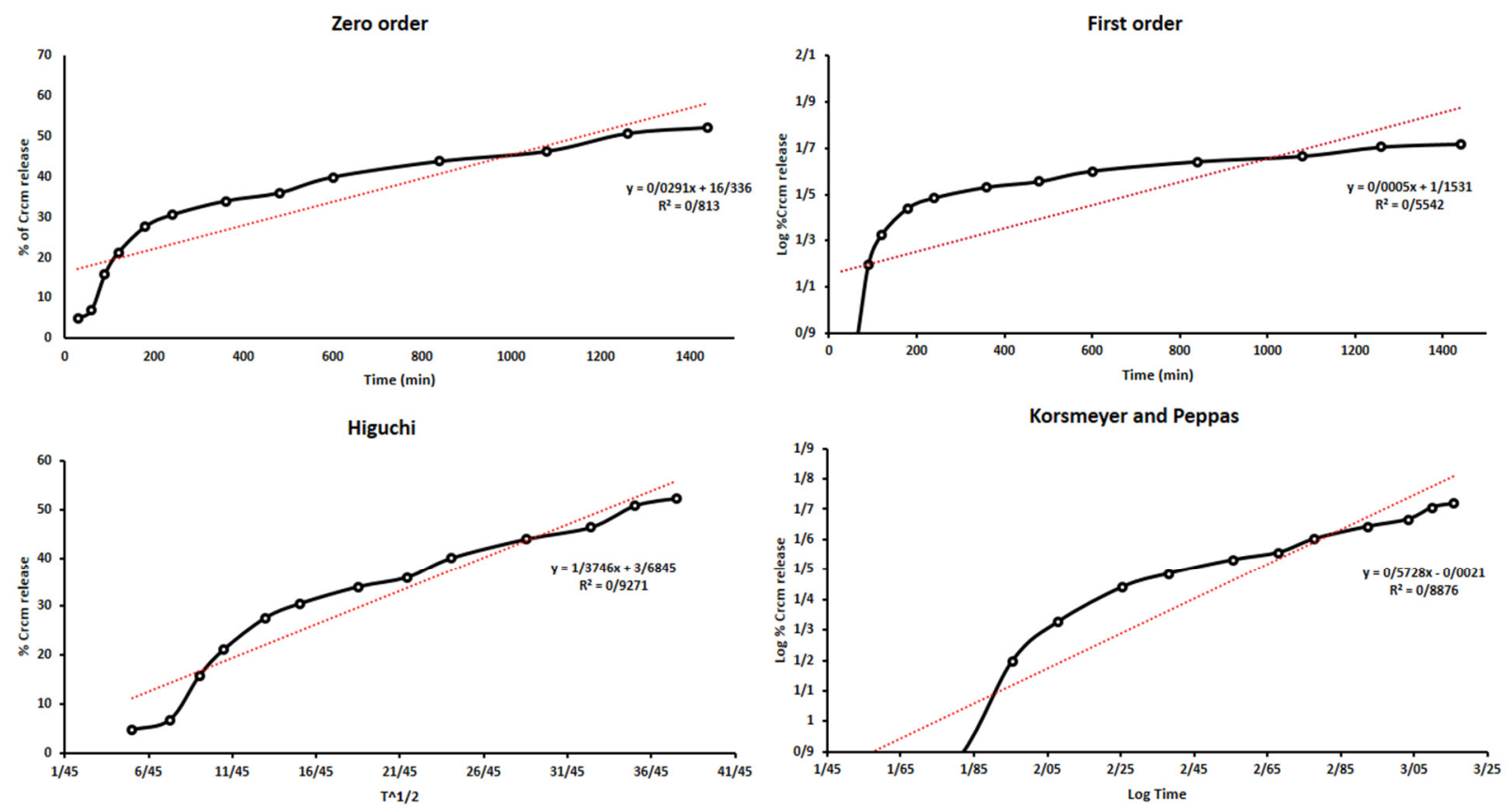

Figure 3. Profiles of different kinetic modes for release of curcumin from microemulsion; the black line is fitting mode of different kinetic release models, and red line is linear fitting.

The effect of different parameters on the release of active ingredients from nanocarriers has been evaluated in several studies [85-87]. Mikesh et al. prepared curcumin microemulsion by water titration approach by biocompatible components for intranasal delivery [88]. In their in vitro release analysis, mucoadhesive microemulsion was found to show more 
prolonged release. Kinetic models have been fitted with release data showing that Fickian is the release model.

\subsection{In Vitro Assessments}

Both free curcumin and curcumin microemulsions diminished the viability of nonmalignant and malignant cells in a concentration-dependent manner (Figure 4). Within the described ranges, the $\mathrm{IC}_{50}$ values of free curcumin and curcumin microemulsions were, respectively, $55.75 \mu \mathrm{g} / \mathrm{mL}$ and $27.46 \mu \mathrm{g} / \mathrm{mL}$ in MCF7 cells, $9.61 \mu \mathrm{g} / \mathrm{mL}$ and $8.24 \mu \mathrm{g} / \mathrm{mL}$ in HepG2 cells, $21.55 \mu \mathrm{g} / \mathrm{mL}$ and $30.24 \mu \mathrm{g} / \mathrm{mL}$ in HUVECs, and $14.79 \mu \mathrm{g} / \mathrm{mL}$ and $37.83 \mu \mathrm{g} / \mathrm{mL}$ in HEK293 cells. Compared to free curcumin, malignant cells were more sensitive to newly synthesized curcumin microemulsions (lower $\mathrm{IC}_{50}$ ). In comparison, the normal cells derived from human embryonic kidney and umbilical vein tissues were more resistant to encapsulated curcumins (higher $\mathrm{IC}_{50}$ ). However, in free and microemulsion formulation, curcumin induced much less toxicity than cisplatin (higher $\mathrm{IC}_{50}$ on both malignant and non-malignant cell lines). This indicates that cisplatin can enhance cancer cell killing much more effectively than newly developed curcumin microemulsions.

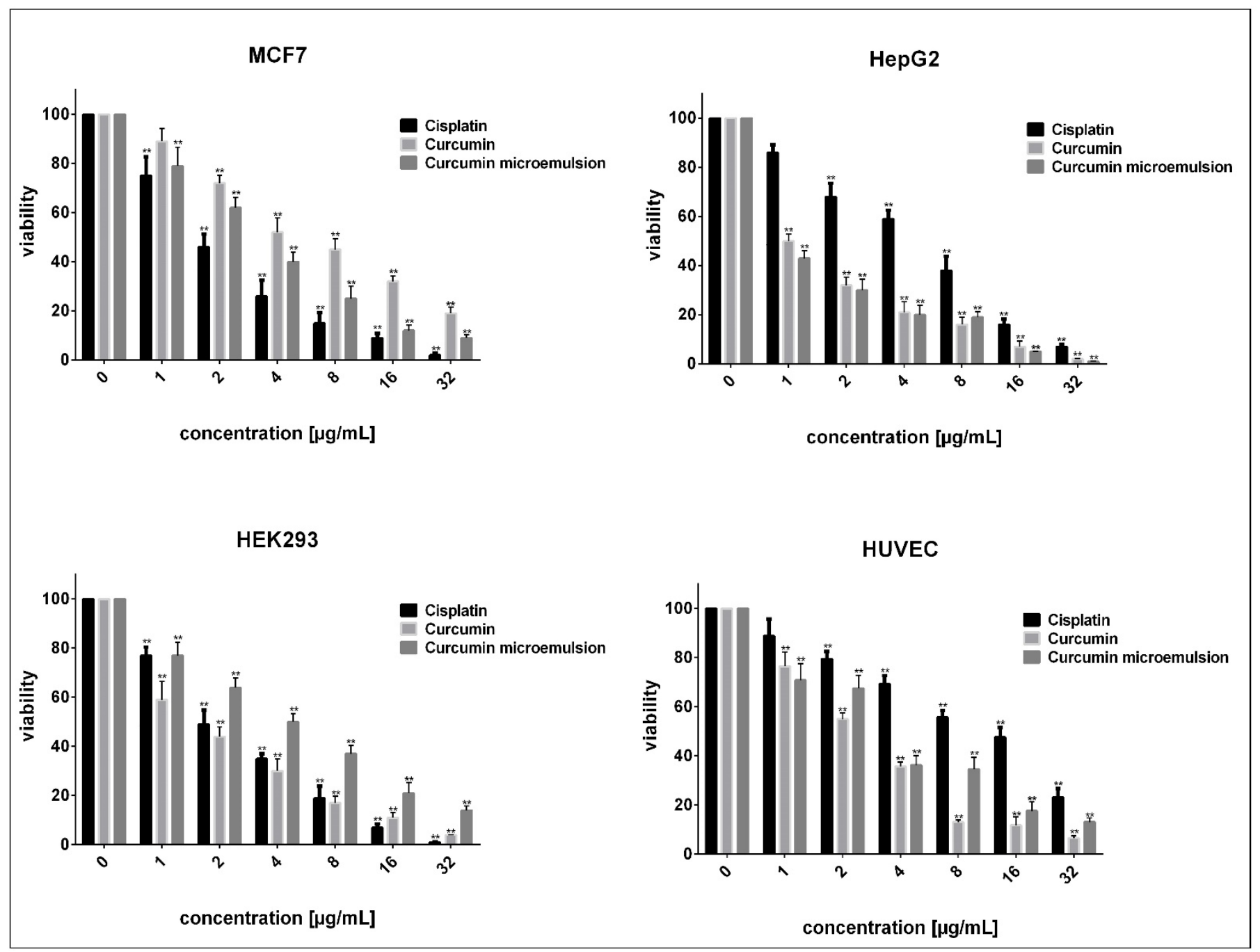

Figure 4. Cytotoxic effects of free curcumin, curcumin microemulsion, and cisplatin (as positive control) on malignant (HepG2 and MCF7) and non-malignant (HUVEC and HEK293) cell lines using MTT assay. The results represent the mean \pm SD of three independent experiments. (** $p<0.05$ compared with untreated cells). 
Later, we aimed to assess the interaction between cisplatin, a conventional alkylating agent, and free/encapsulated curcumin in malignant cells. Results of combination analysis revealed that a combination of free curcumin and cisplatin mediated additive or mild antagonistic effects on HepG2 (Figure 5A) and MCF7 (Figure 5B) cells (CI > 1). Interestingly, we observed a synergistic relationship between curcumin microemulsions and cisplatin in all affected fractions of HepG2 (Figure 5A) and MCF7 (Figure 5B) cells $(\mathrm{CI}<1$ ). These findings suggest that the newly developed curcumin microemulsions enhance cisplatin cytotoxicity in cells derived from liver or breast tissues of cancer patients.

\section{A}

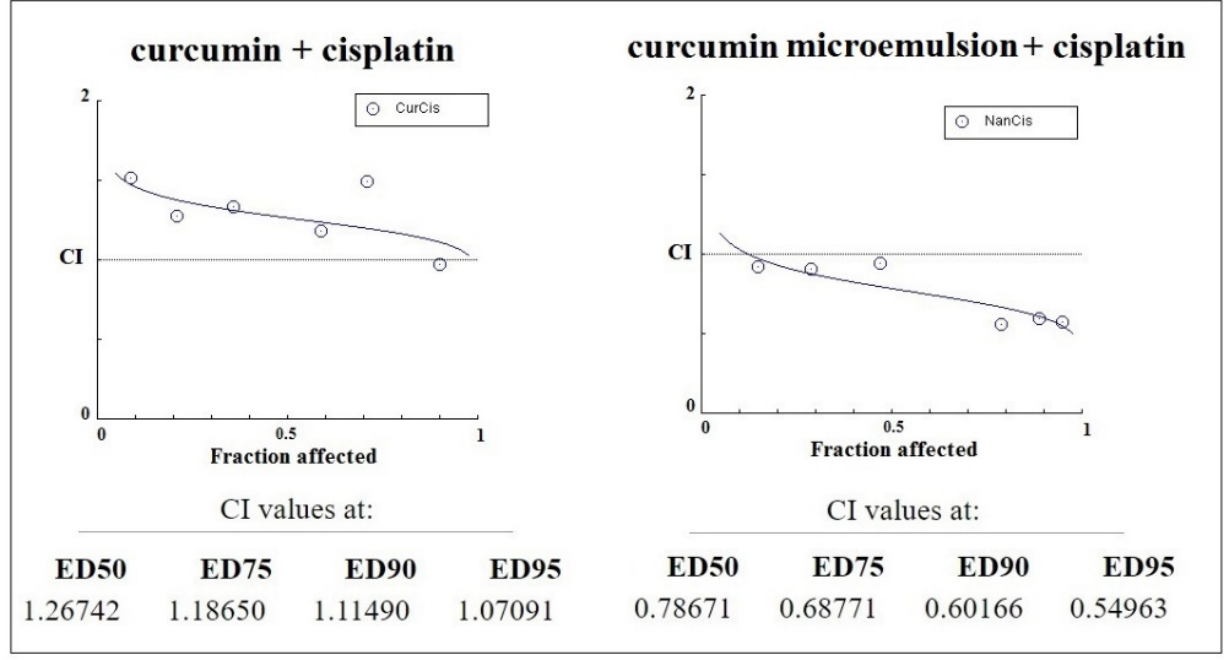

B

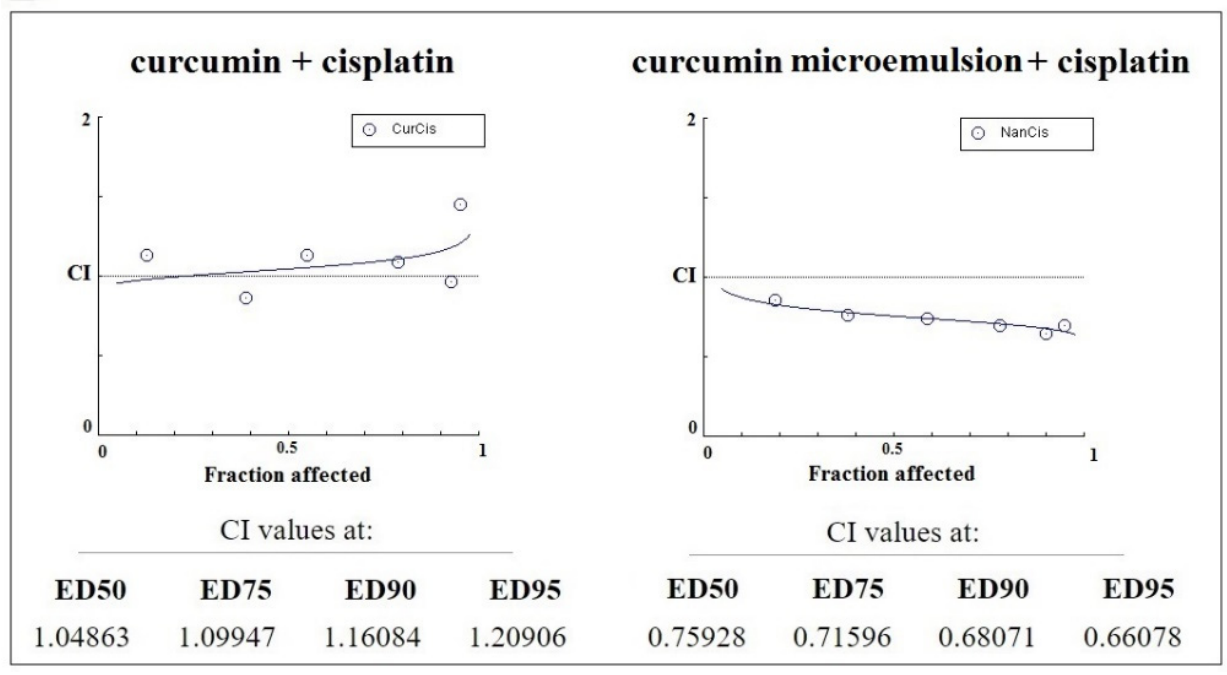

Figure 5. Analysis of drug interaction between free or encapsulated curcumin and cisplatin in (A) HepG2 and (B) MCF7 cancer cells in different effective doses (EDs).

Combination therapy enhances the efficacy of anti-cancer drugs compared with the mono-therapy approach and reduces drug resistance or adverse effects $[89,90]$. Cisplatin, an alkylating agent widely used in treating different cancers, induced putative toxicity and is the principal cause of nephrotoxicity, hepatotoxicity, ototoxicity, and allergic reactions [91,92]. In this regard, many efforts have been made to exploit the synergy between cisplatin and the anti-cancer drugs with totally different mechanisms of action, including encapsulation of one or two drugs in a newly formulated nanoscale delivery system. We hypothesized that if cisplatin synergizes with another anti-cancer drug, lower concentrations of cisplatin are needed in combination with that agent to achieve similar cytotoxicity to 
cancer cells. We performed combination drug analysis to investigate if cisplatin synergizes with curcumin microemulsions in cancer cells and found a synergistic relationship between the two drugs, which might be a promising outcome. However, our results did not entirely agree with the findings reported by Notarbartolo et al. [10], who found a synergistic relationship between free curcumin and cisplatin in HA22T/VGH, as a poorly differentiated hepatoma cell line. Still, we observed a promising cell-death-inducing capability of the synthesized microemulsions against malignant liver and breast cells. Compared with free curcumin, nano-curcumin exerted higher cytotoxicity in malignant cells, specifically in MCF7 breast cancer cells. This is because our new formulation increased the solubility of curcumin, which is a slightly soluble drug, and enhanced its delivery to the tumor site. Overall, the incorporation of curcumin in microemulsion increased curcumin cytotoxicity and cisplatin cytotoxicity against cancer cells. Hence, it can be suggested that the synthesized curcumin microemulsions could serve as a versatile and efficient nano-delivery system for curcumin, a drug that practically requires solubilizing agents for delivery.

\subsection{Biochemical Assessments}

Table 1 shows serum biochemical parameters and oxidative stress status in rats. Rats in the control group showed normal serum BUN and creatinine levels, normal liver enzymes, malondialdehyde (MDA), and liver antioxidant enzyme activities. The animals treated with curcumin microemulsions also had healthy liver and kidney function, normal lipid peroxidation level, and enhanced liver antioxidant-enzyme activities. The thioacetamidetreated rats had elevated serum AST and ALT levels in contrast to the control rats $(p<0.05$ and $p<0.01$, respectively). Serum BUN and creatinine levels also increased in rats who received the subcutaneous injection of thioacetamide $(p<0.001)$. The thioacetamidetreated rats also had reduced liver catalase and SOD activities $(p<0.01$ and $p<0.05$, respectively) with a substantial rise in serum MDA levels $(p<0.05)$. Treatment with curcumin microemulsions restored the elevated levels of BUN, creatinine, AST, and serum MDA to the normal levels. Treatment with curcumin microemulsions also improved liver catalase and superoxide dismutase activities in thioacetamide-treated rats compared to the untreated thioacetamide-intoxicated rats. The current work showed the potential antioxidant and hepatoprotective effects the curcumin microemulsion. The potential antioxidant activity of curcumin microemulsions after oxidative stress induction was investigated in rats. Activities of serum antioxidant enzymes in the liver, serum liver enzymes, kidney function markers, lipid peroxidation, and possible liver toxicity and nephrotoxicity were examined. Four weeks of intraperitoneal injections of curcumin microemulsions caused a significant elevation in liver SOD and catalase activities and a non-significant decrease in liver MDA content.

Table 1. Serum biochemical parameters and lipid peroxidation in rats. ${ }^{*}, * *$ and ${ }^{* * *}$ indicate a statistically significant difference with $p<0.05, p<0.01$, and $p<0.001$, respectively, for the control group.

\begin{tabular}{|c|c|c|c|c|}
\hline \multirow[b]{2}{*}{ Item } & \multicolumn{4}{|c|}{ Treatment } \\
\hline & Control & $\begin{array}{l}\text { Curcumin Microemulsion } \\
\qquad 30 \mathrm{mg} / \mathrm{kg}\end{array}$ & $\begin{array}{l}\text { Thioacetamide } \\
100 \mathrm{mg} / \mathrm{kg}\end{array}$ & $\begin{array}{l}\text { Thioacetamide } 100 \mathrm{mg} / \mathrm{kg}+ \\
\text { Curcumin } 30 \mathrm{mg} / \mathrm{kg}\end{array}$ \\
\hline AST (U/L) & $78.0 \pm 8.6$ & $66.3 \pm 10.0$ & $96.7 * \pm 15.0$ & $77.8 \pm 11.7$ \\
\hline $\operatorname{ALT}(\mathrm{U} / \mathrm{L})$ & $31.1 \pm 4.7$ & $36.2 \pm 4.1$ & $48.3^{* *} \pm 9.6$ & $41.2 * \pm 8.1$ \\
\hline MDA (nmol/mL) & $137.9 \pm 20.8$ & $130.6 \pm 21.0$ & $164.0 * \pm 21.5$ & $141.7 \pm 13.1$ \\
\hline $\mathrm{BUN}$ (mg/dL) & $14.3 \pm 2.8$ & $13.8 \pm 2.0$ & $24.2^{* * *} \pm 4.5$ & $15.2 \pm 1.6$ \\
\hline Creatinine $(\mathrm{mg} / \mathrm{dL})$ & $0.95 \pm 0.17$ & $1.1 \pm 0.21$ & $2.01^{* * *} \pm 0.39$ & $1.20 \pm 0.48$ \\
\hline $\begin{array}{c}\text { Liver SOD } \\
\text { (U/g protein) }\end{array}$ & $18.0 \pm 2.3$ & $26.0^{* *} \pm 8.0$ & $11.7^{*} \pm 2.2$ & $16.5 \pm 2.4$ \\
\hline $\begin{array}{c}\text { Liver CAT } \\
\text { (U/g protein) }\end{array}$ & $52.5 \pm 8.4$ & $62.9^{*} \pm 79.9$ & $38.1^{* *} \pm 7.4$ & $44.5 \pm 6.8$ \\
\hline
\end{tabular}


Previous reports have demonstrated the antioxidant properties of free curcumin and curcumin microemulsions in experimental animals $[93,94]$. Treatment with curcumin microemulsions also led to a significant hepatoprotective and nephroprotective effect in thioacetamide-intoxicated rats. While numerous studies have inspected the effects of curcumin on liver and kidney function, few works have been conducted on in vivo effects of curcumin microemulsions. In the current work, liver sections showed diffuse hepatocyte ballooning, which is an indicator of reversible liver damage. These histopathological changes were reduced in rats treated with curcumin microemulsions. The decrease in hepatocyte fatty change was accompanied by an improvement in liver and serum antioxidant status. It seems that antioxidant activity is the fundamental mechanism of the hepatoprotective effects of curcumin microemulsions. This confirmed the results of previous studies showing that curcumin microemulsion formulation could increase the hepatoprotective and antioxidant potential of curcumin [95].

The outcomes of the current study revealed that a four-week injection of curcumin microemulsions could reduce the liver histopathological lesions in thioacetamide-treated rats; however, the liver changes were still present, which could be due to the short-term administration of microemulsions. Thioacetamide is an excellent model for inducing liver and kidney damage. By performing in vitro cytotoxic assays, we investigated the celldeath-inducing capability of newly developed curcumin microemulsions compared to free curcumin. Interestingly, in malignant MCF7 and HepG2 cells, curcumin microemulsions induced higher concentration-dependent toxicity than free curcumin. Simultaneously, no reduction in the viability was observed following treatment of normal human cells with curcumin microemulsions, which is a promising result considering that many anti-cancer agents cause undesirable effects, i.e., normal cell death [96].

\subsection{Histological Results}

The results of histopathological investigation of the liver and kidney are presented in Figures 6-8. As shown in Figure 6, control rats had normal histology with well-arranged hepatocytes (Figure 6A). The group that received the curcumin microemulsions also had normal morphology, as seen in Figure 6B. The rats that received intraperitoneal injections of thioacetamide showed perinuclear fat deposition in the cytoplasm (Figure 6C), which were ameliorated in rats receiving the combined administration of thioacetamide and curcumin microemulsions (Figure 6D). Periodic acid-Schiff (PAS) staining of the liver of control rats and curcumin-treated rats was quite normal. As seen in Figure 7A,B, hepatocytes and hepatic cords were quite normal too. In contrast, liver histopathological investigation of thioacetamide-treated rats showed severe fatty change and increasing glycogen storage in the cytoplasm (Figure 7C). In the liver of thioacetamide-intoxicated rats treated with intraperitoneal injections of $30 \mathrm{mg} / \mathrm{kg}$ curcumin microemulsion, a decrease in fatty change was observed (Figure 7D).

Kidney micrographs of the control and curcumin microemulsion-treated group at a dose of $30 \mathrm{mg} / \mathrm{kg}$ were normal with normal glomerulus and normal tubules (Figure 8A,B). The kidney micrograph of thioacetamide-treated rats with a dose of $30 \mathrm{mg} / \mathrm{kg}$ showed extensive bleeding (Figure $8 \mathrm{C}$ ). Treatment with curcumin microemulsions reduced thioacetamideintoxicated histological changes in kidneys (Figure 8D). 


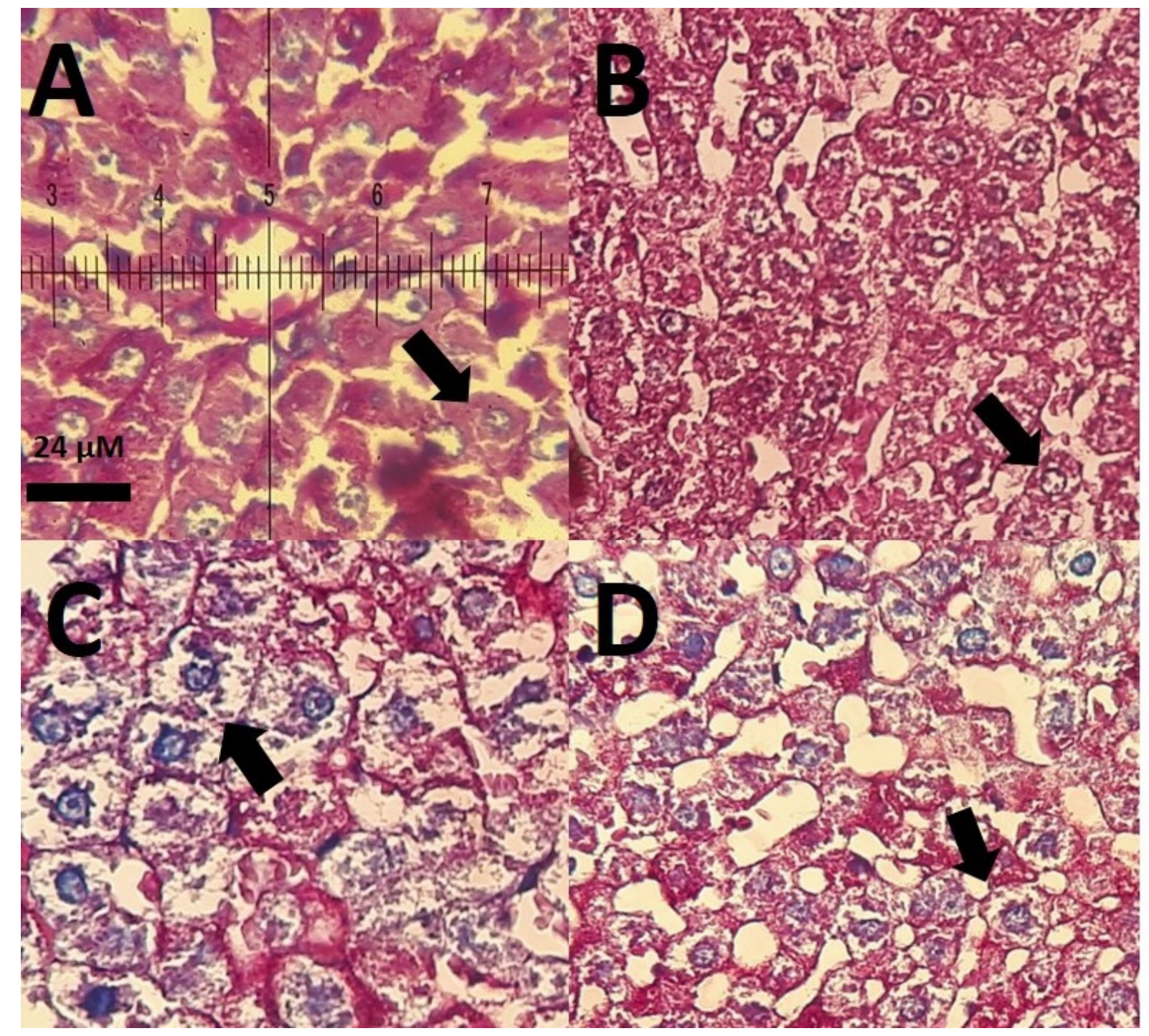

Figure 6. (A) Alcian blue-stained section liver section of a control rat showing normal hepatocytes, well-arranged hepatic cords, normal portal triads, and normal central vein $(\mathrm{CV})$. Bar $=24 \mu \mathrm{m}(\times 40)$. (B) Liver section of a rat received the $30 \mathrm{mg} / \mathrm{kg}$ dose of curcumin microemulsions, showing normal morphology of hepatocytes (arrow) and well-arranged hepatic cords. As seen, no histopathological injury is observed. Alcian blue staining $(\times 40)$. (C) liver sections of a rat thioacetamide-treated rat, intensive intra-cytoplasmic fat deposition is observed (arrow); (D) liver section of a thioacetamide-intoxicated rat treated with intraperitoneal injections of $30 \mathrm{mg} / \mathrm{kg}$ curcumin microemulsions, showing a reduction in cytoplasmic vacuolation (arrow point). Alcian blue staining (40× magnification). Scale bar indicates $40 \mu \mathrm{m}$. 


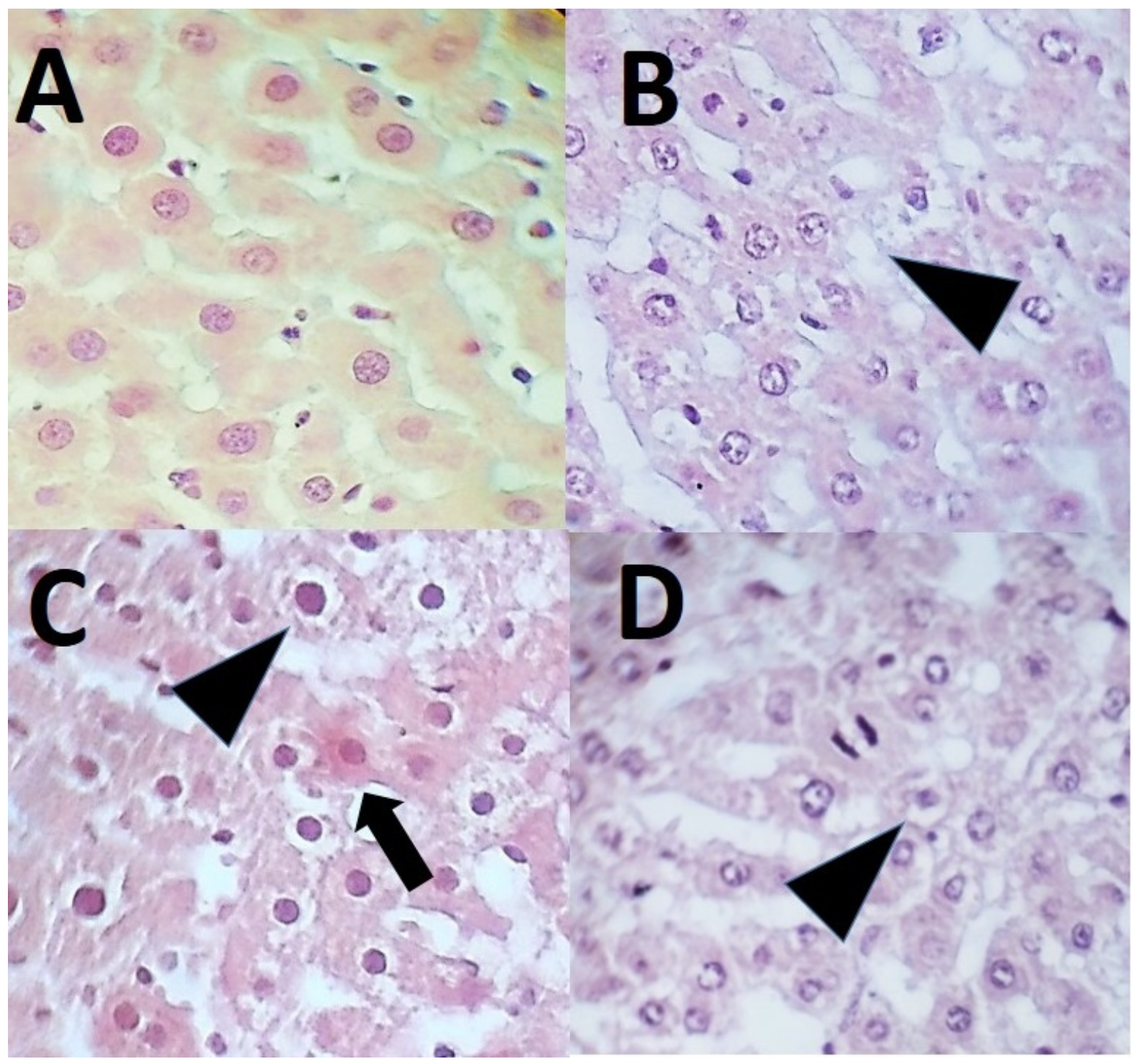

Figure 7. (A) Periodic acid-Schiff (PAS) section liver section of a control rat showing liver morphology with normal hepatocytes and hepatic cords. (B) The liver section of a rat received the $30 \mathrm{mg} / \mathrm{kg}$ dose of curcumin microemulsions, showing normal hepatocytes and hepatic cords, indicating normal histology of the liver. (C) liver sections of a thioacetamideintoxicated rat, intra-cytoplasmic fat vacuoles are observed (arrow); (D) liver section of a thioacetamide-intoxicated rat treated with intraperitoneal injections of $30 \mathrm{mg} / \mathrm{kg}$ curcumin microemulsions, showing a decrease in fatty change (arrow point). Periodic acid-Schiff (PAS) staining (40× magnification). 


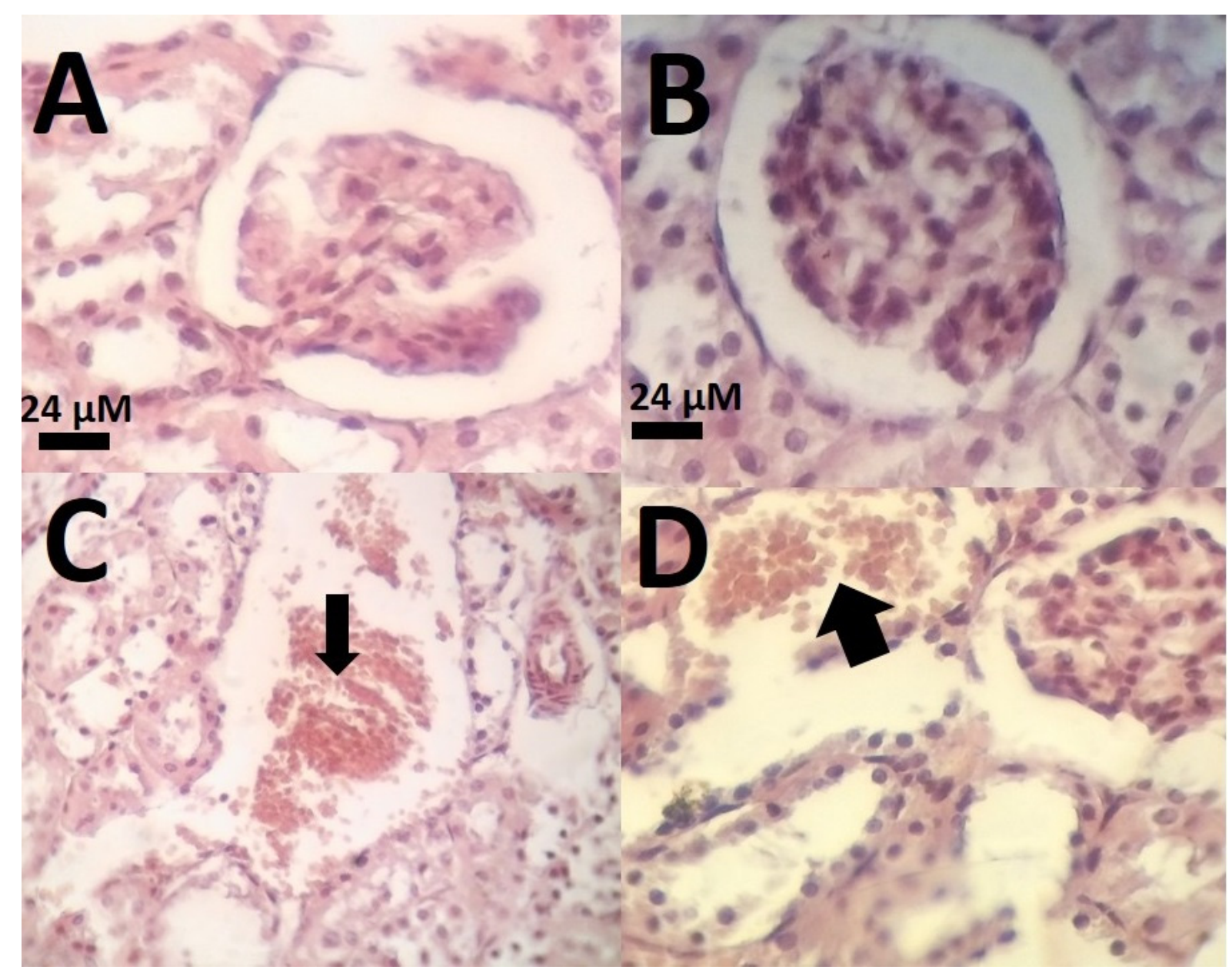

Figure 8. (A) Kidney micrograph of a normal control rat, showing normal glomerulus and normal tubules. (B): renal micrograph of a rat treated with curcumin microemulsions at a $30 \mathrm{mg} / \mathrm{kg}$ dose with normal kidney structure. (C): kidney of a thioacetamide-treated rat at a dose of $30 \mathrm{mg} / \mathrm{kg}$; extensive bleeding is present (arrow). (D): A kidney PAS-stained section of a thioacetamide-intoxicated rat treated with curcumin microemulsions at a dose of $30 \mathrm{mg} / \mathrm{kg}$ shows a reduction in blood congestion in the kidney (arrow). PAS staining. (40× magnification).

\section{Conclusions}

The F127-based microemulsions synthesized in this work and loaded with curcumin showed high encapsulation efficiency and prolonged release of the drug. In vitro studies revealed that cancer cells were more sensitive to curcumin microemulsions than normal human cells. In vivo assessments indicated protective effects against thioacetamide-induced oxidative stress and hepatic injury in rats. Overall, the microemulsions prepared in this study represent a potentially effective drug delivery system for curcumin in advanced anticancer therapies.

Supplementary Materials: The following are available online at https: / www.mdpi.com/2079-4 991/11/3/817/s1, Figure S1: The optimized structures of compounds studied in the present work, Figure S2: The initial (left) and final (right) structures of the different studied configurations and the related interaction energy (in $\mathrm{kJ} / \mathrm{mol}$ ), Figure S3: The molecular graph of the CURF1 complex obtained from the DFT calculation, Figure S4: The distances between the $\mathrm{H}$ and $\mathrm{O}$ atoms at the sites of existence the intermolecular hydrogen bond for A: CURF2 and B: CURSodium3 complexes, Figure S5: Correlation between the calculated $\nabla^{2} \varrho(r)$ with the $E_{H B}^{*}$ energies, Figure S6: The HOMO and LUMO orbitals of the CURF2 complex at M06-2X/6-31G* method, Table S1: The selected topological parameters of investigated complexes (in a.u.) and the energies of the intermolecular hydrogen bond $\left(E_{H B}^{*}\right.$ in $\left.\mathrm{kJ} \mathrm{mol}^{-1}\right)$ ) for all studied complexes, calculated at the M06-2X/6-31G* level, Table 
S2: The NBO analysis of all studied configurations, Table S3: The values of $\mid \mathrm{HOMO}_{\left(\text {monomer }_{1}\right)^{-}}$

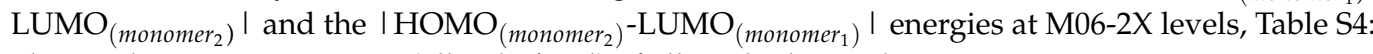
Thermodynamic parameters (all in $\mathrm{kJ} / \mathrm{mol}$ ) of all studied complexes.

Author Contributions: Conceptualization, S.S. and A.R.; methodology, A.R., M.R.H., S.S., M.Z., M.B. (Mahmood Barani), M.B. (Muhammad Bilal), E.S.; investigation, A.R., M.R.H., S.S., M.Z., M.B. (Mahmood Barani), M.B. (Muhammad Bilal), E.S.; resources, S.S., A.R., M.R.H., M.Z., M.B. (Mahmood Barani), F.B., M.B. (Muhammad Bilal), E.S.; writing—original draft preparation, A.R., M.R.H., S.S., M.Z., M.B. (Muhammad Bilal), E.S.; writing—review and editing, F.B.; supervision, S.S.; All authors have read and agreed to the published version of the manuscript.

Funding: The authors would like to thank Zahedan University of Medical Sciences for providing financial support for this study (grant number 10267).

Institutional Review Board Statement: The study was conducted according to the guidelines of the Declaration of Helsinki and approved by the Ethics Committee of Zahedan University of Medical Sciences (IR.ZAUMS.REC.1399.517) and University of Zabol (IR.UOZ.ERC.1399.009).

Informed Consent Statement: Not applicable.

Data Availability Statement: Data are included within this article.

Conflicts of Interest: The authors declare no conflict of interest.

\section{References}

1. Li, H.; Sureda, A.; Devkota, H.P.; Pittalà, V.; Barreca, D.; Silva, A.S.; Tewari, D.; Xu, S.; Nabavi, S.M. Curcumin, the golden spice in treating cardiovascular diseases. Biotechnol. Adv. 2020, 38, 107343. [CrossRef] [PubMed]

2. Ahmad, N.; Ahmad, R.; Al-Qudaihi, A.; Alaseel, S.E.; Fita, I.Z.; Khalid, M.S.; Pottoo, F.H. Preparation of a novel curcumin nanoemulsion by ultrasonication and its comparative effects in wound healing and the treatment of inflammation. RSC Adv. 2019, 9, 20192-20206. [CrossRef]

3. Barani, M.; Mirzaei, M.; Torkzadeh-Mahani, M.; Adeli-Sardou, M. Evaluation of Carum-loaded Niosomes on Breast Cancer Cells: Physicochemical Properties, In Vitro Cytotoxicity, Flow Cytometric, DNA Frag-mentation and Cell Migration Assay. Sci. Rep. 2019, 9, 1-10. [CrossRef]

4. Barani, M.; Mirzaei, M.; Torkzadeh-Mahani, M.; Lohrasbi-Nejad, A.; Nematollahi, M.H. A new formulation of hydrophobin-coated niosome as a drug carrier to cancer cells. Mater. Sci. Eng. C 2020, 113, 110975. [CrossRef] [PubMed]

5. Barani, M.; Mirzaei, M.; Torkzadeh-Mahani, M.; Nematollahi, M.H. Lawsone-loaded Niosome and its an-titumor activity in MCF-7 breast Cancer cell line: A Nano-herbal treatment for Cancer. DARU J. Pharm. Sci. 2018, 26, 11-17. [CrossRef]

6. Torkzadeh-Mahani, M.; Hajizadeh, M.R.; Maleki, H.; Barani, M.; Fahmidehkar, M.A.; Mahmoodi, M. In vitro cytotoxicity assay of D-limonene niosomes: An efficient nano-carrier for enhancing solubility of plant-extracted agents. Res. Pharm. Sci. 2019, 14, 448-458. [CrossRef]

7. Hajizadeh, M.R.; Parvaz, N.; Barani, M.; Khoshdel, A.; Fahmidehkar, M.A.; Mahmoodi, M.; Torkzadeh-Mahani, M. Diosgeninloaded niosome as an effective phytochemical nanocarrier: Physicochemical char-acterization, loading efficiency, and cytotoxicity assay. DARU J. Pharm. Sci. 2019, 27, 329-339. [CrossRef]

8. Rahdar, A.; Taboada, P.; Hajinezhad, M.R.; Barani, M.; Beyzaei, H. Effect of tocopherol on the properties of Pluronic F127 microemulsions: Physico-chemical characterization and in vivo toxicity. J. Mol. Liq. 2019, 277, 624-630. [CrossRef]

9. Cao, J.; Liu, Y.; Jia, L.; Zhou, H.-M.; Kong, Y.; Yang, G.; Jiang, L.-P.; Li, Q.-J.; Zhong, L.-F. Curcumin induces apoptosis through mitochondrial hyperpolarization and mtDNA damage in human hepatoma G2 cells. Free. Radic. Biol. Med. 2007, 43, 968-975. [CrossRef]

10. Notarbartolo, M.; Poma, P.; Perri, D.; Dusonchet, L.; Cervello, M.; D'Alessandro, N. Antitumor effects of curcumin, alone or in combination with cisplatin or doxorubicin, on human hepatic cancer cells. Analysis of their possible relationship to changes in NF-kB activation levels and in IAP gene expression. Cancer Lett. 2005, 224, 53-65. [CrossRef]

11. Barui, S.; Saha, S.; Mondal, G.; Haseena, S.; Chaudhuri, A. Simultaneous delivery of doxorubicin and curcumin encapsulated in liposomes of pegylated RGDK-lipopeptide to tumor vasculature. Biomaterials 2014, 35, 1643-1656. [CrossRef]

12. Barani, M.; Nematollahi, M.H.; Zaboli, M.; Mirzaei, M.; Torkzadeh-Mahani, M.; Pardakhty, A.; Karam, G.A. In silico and in vitro study of magnetic niosomes for gene delivery: The effect of ergosterol and cholesterol. Mater. Sci. Eng. C 2019, 94, 234-246. [CrossRef] [PubMed]

13. Barani, M.; Sabir, F.; Rahdar, A.; Arshad, R.; Kyzas, G.Z. Nanotreatment and Nanodiagnosis of Prostate Cancer: Recent Updates. Nanomaterials 2020, 10, 1696. [CrossRef]

14. Barani, M.; Torkzadeh-Mahani, M.; Mirzaei, M.; Nematollahi, M.H. Comprehensive Evaluation of Gene Expression in Negative and Positive Trigger-based Targeting Niosomes in HEK-293 Cell Line. Iran. J. Pharm. Res. 2020, 19, 166-180.

15. Das, S.S.; Bharadwaj, P.; Bilal, M.; Barani, M.; Rahdar, A.; Taboada, P.; Bungau, S.; Kyzas, G.Z. Stimu-li-Responsive Polymeric Nanocarriers for Drug Delivery, Imaging, and Theragnosis. Polymers 2020, 12, 1397. [CrossRef] 
16. Nikazar, S.; Barani, M.; Rahdar, A.; Zoghi, M.; Kyzas, G.Z. Photo-and Magnetothermally Responsive Nanomaterials for Therapy, Controlled Drug Delivery and Imaging Applications. ChemistrySelect 2020, 5, 12590-12609. [CrossRef]

17. Rahdar, A.; Hajinezhad, M.R.; Nasri, S.; Beyzaei, H.; Barani, M.; Trant, J.F. The synthesis of methotrex-ate-loaded F127 microemulsions and their in vivo toxicity in a rat model. J. Mol. Liquids 2020, 313, 113449. [CrossRef]

18. Torkzadeh-Mahani, M.; Zaboli, M.; Barani, M.; Torkzadeh-Mahani, M. A combined theoretical and experimental study to improve the thermal stability of recombinant D-lactate dehydrogenase immobilized on a novel superparamagnetic Fe3O4NPs@ metal-organic framework. Appl. Organometal. Chem. 2020, 34, e5581. [CrossRef]

19. Bilal, M.; Barani, M.; Sabir, F.; Rahdar, A.; Kyzas, G.Z. Nanomaterials for the treatment and diagnosis of Alzheimer's disease: An overview. NanoImpact 2020, 20, 100251. [CrossRef]

20. Ghazy, E.; Kumar, A.; Barani, M.; Kaur, I.; Rahdar, A.; Behl, T. Scrutinizing the therapeutic and diagnostic potential of nanotechnology in thyroid cancer: Edifying drug targeting by nano-oncotherapeutics. J. Drug Deliv. Sci. Technol. 2021, 61, 102221. [CrossRef]

21. Ghazy, E.; Rahdar, A.; Barani, M.; Kyzas, G.Z. Nanomaterials for Parkinson disease: Recent progress. J. Mol. Struct. 2021, 1231, 129698. [CrossRef]

22. Mukhtar, M.; Bilal, M.; Rahdar, A.; Barani, M.; Arshad, R.; Behl, T.; Brisc, C.; Banica, F.; Bungau, S. Nano-materials for Diagnosis and Treatment of Brain Cancer: Recent Updates. Chemosensors 2020, 8, 117. [CrossRef]

23. Rahdar, A.; Hajinezhad, M.R.; Sargazi, S.; Barani, M.; Bilal, M.; Kyzas, G.Z. Deferasirox-loaded pluronic nanomicelles: Synthesis, characterization, in vitro and in vivo studies. J. Mol. Liq. 2021, 323, 114605. [CrossRef]

24. Bilal, M.; Mehmood, S.; Rasheed, T.; Iqbal, H. Bio-catalysis and biomedical perspectives of magnetic nanoparticles as versatile carriers. Magnetochemistry 2019, 5, 42. [CrossRef]

25. Rasheed, T.; Nabeel, F.; Raza, A.; Bilal, M.; Iqbal, H. Biomimetic nanostructures/cues as drug delivery systems: A review. Mater. Today Chem. 2019, 13, 147-157. [CrossRef]

26. Munir, S.; Shah, A.A.; Rahman, H.; Bilal, M.; Rajoka, M.S.R.; Khan, A.A.; Khurshid, M. Nanozymes for medical biotechnology and its potential applications in biosensing and nanotherapeutics. Biotechnol. Lett. 2020, 42, 357-373. [CrossRef] [PubMed]

27. Ain, Q.U.; Munir, H.; Jelani, F.; Anjum, F.; Bilal, M. Antibacterial potential of biomaterial derived nano-particles for drug delivery application. Mater. Res. Express 2020, 6, 125426. [CrossRef]

28. Rahdar, A.; Hajinezhad, M.R.; Bilal, M.; Askari, F.; Kyzas, G.Z. Behavioral effects of zinc oxide nanoparticles on the brain of rats. Inorg. Chem. Commun. 2020, 119, 108131. [CrossRef]

29. Raza, A.; Hayat, U.; Bilal, M.; Iqbal, H.M.; Wang, J.Y. Zein-based micro-and nano-constructs and biologically therapeutic cues with multi-functionalities for oral drug delivery systems. J. Drug Deliv. Sci. Technol. 2020, 58, 101818. [CrossRef]

30. Sun, M.; Su, X.; Ding, B.; He, X.; Liu, X.; Yu, A.; Lou, H.; Zhai, G. Advances in nanotechnology-based de-livery systems for curcumin. Nanomedicine 2012, 7, 1085-1100. [CrossRef] [PubMed]

31. El Asbahani, A.; Miladi, K.; Badri, W.; Sala, M.; Addi, E.A.; Casabianca, H.; El Mousadik, A.; Hartmann, D.; Jilale, A.; Renaud, F.; et al. Essential oils: From extraction to encapsulation. Int. J. Pharm. 2015, 483, 220-243. [CrossRef]

32. Tadros, T.F. Emulsion science and technology: A general introduction. Emul. Sci. Technol. 2009, 1, 1-55.

33. Donsì, F.; Ferrari, G. Essential oil nanoemulsions as antimicrobial agents in food. J. Biotechnol. 2016, 233, 106-120. [CrossRef]

34. Mishra, M. Handbook of Encapsulation and Controlled Release; CRC Press: Boca Raton, FL, USA, 2015.

35. Fanun, M. Microemulsions: Properties and Applications; CRC Press: Boca Raton, FL, USA, 2008.

36. Fanun, M. Microemulsions as delivery systems. Curr. Opin. Colloid Interface Sci. 2012, 17, 306-313. [CrossRef]

37. Fernández-Peña, L.; Gutiérrez-Muro, S.; Guzmán, E.; Lucia, A.; Ortega, F.; GRubio, R. Oil-In-Water Microemulsions for Thymol Solubilization. Colloids Interfaces 2019, 3, 64. [CrossRef]

38. Davarpanah, A.M.; Rahdar, A.; Dastnae, M.A.; Zeybek, O.; Beyzaei, H. (1-x) BaFe12O19/xCoFe2O4 hard/soft magnetic nanocomposites: Synthesis, physical characterization, and antibacterial activities study. J. Mol. Struct. 2019, 1175, 445-449. [CrossRef]

39. Rahdar, A.; Aliahmad, M.; Samani, M.; HeidariMajd, M.; Susan, A.B.H. Synthesis and characterization of highly efficacious Fe-doped ceria nanoparticles for cytotoxic and antifungal activity. Ceram. Int. 2019, 45, 7950-7955. [CrossRef]

40. Rahdar, A.; Hajinezhad, M.R.; Hamishekar, H.; Ghamkhari, A.; Kyzas, G.Z. Copolymer/graphene oxide nanocomposites as potential anti-cancer agents. Polym. Bull. 2020, 1-22. [CrossRef]

41. Rahdar, A.; Beyzaei, H.; Askari, F.; Kyzas, G.Z. Gum-based cerium oxide nanoparticles for antimicrobial assay. Appl. Phys. A 2020, 126, 1-9. [CrossRef]

42. Rahdar, A.; Hajinezhad, M.R.; Sivasankarapillai, V.S.; Askari, F.; Noura, M.; Kyzas, G.Z. Synthesis, characterization, and intraperitoneal biochemical studies of zinc oxide nanoparticles in Rattus norvegicus. Appl. Phys. A 2020, 126, 1-9. [CrossRef]

43. Saravani, R.; Sargazi, S.; Saravani, R.; Rabbani, M.; Rahdar, A.; Taboada, P. Newly crocin-coated magnetite nanoparticles induce apoptosis and decrease VEGF expression in breast carcinoma cells. J. Drug Deliv. Sci. Technol. 2020, 60, 101987. [CrossRef]

44. Sivasankarapillai, V.S.; Somakumar, A.K.; Joseph, J.; Nikazar, S.; Rahdar, A.; Kyzas, G.Z. Cancer theranostic applications of MXene nanomaterials: Recent updates. Nano Struct. Nano Objects 2020, 22, 100457. [CrossRef]

45. Sivasankarapillai, V.S.; Pillai, A.M.; Rahdar, A.; Sobha, A.P.; Das, S.S.; Mitropoulos, A.C.; Mokarrar, M.H.; Kyzas, G.Z. On Facing the SARS-CoV-2 (COVID-19) with Combination of Nanomaterials and Medicine: Possible Strategies and First Challenges. Nanomaterials 2020, 10, 852. [CrossRef] 
46. Sayadi, K.; Rahdar, A.; Hajinezhad, M.R.; Nikazar, S.; Susan, A.B.H.; Sayadi, K. Atorvastatin-loaded SBA-16 nanostructures: Synthesis, physical characterization, and biochemical alterations in hyperlipidemic rats. J. Mol. Struct. 2020, $1202,127296$. [CrossRef]

47. Dhumal, D.M.; Kothari, P.R.; Kalhapure, R.S.; Akamanchi, K.G. Self-microemulsifying drug delivery system of curcumin with enhanced solubility and bioavailability using a new semi-synthetic bicephalous heterolipid: In vitro and in vivo evaluation. RSC Adv. 2015, 5, 90295-90306. [CrossRef]

48. Petchsomrit, A.; Sermkaew, N.; Wiwattanapatapee, R. Hydroxypropylmethyl cellulose-based sponges loaded selfmicroemulsifying curcumin: Preparation, characterization, and in vivo oral absorption studies. J. Appl. Polym. Sci. 2016, 133. [CrossRef]

49. Habib, F.; El-Mahdy, M.; Maher, S. Microemulsions for ocular delivery: Evaluation and characterization. J. Drug Deliv. Sci. Technol. 2011, 21, 485-489. [CrossRef]

50. James-Smith, M.A.; Shekhawat, D.; Cheung, S.; Moudgil, B.M.; Shah, D.O. Effect of chain length on binding of fatty acids to Pluronics in microemulsions. Colloids Surfaces B Biointerfaces 2008, 62, 5-10. [CrossRef]

51. Sahu, A.; Kasoju, N.; Goswami, P.; Bora, U. Encapsulation of curcumin in Pluronic block copolymer mi-celles for drug delivery applications. J. Biomater. Appl. 2011, 25, 619-639. [CrossRef] [PubMed]

52. Basak, R.; Bandyopadhyay, R. Encapsulation of Hydrophobic Drugs in Pluronic F127 Micelles: Effects of Drug Hydrophobicity, Solution Temperature, and pH. Langmuir 2013, 29, 4350-4356. [CrossRef]

53. Maulvi, F.A.; Desai, A.R.; Choksi, H.H.; Patil, R.J.; Ranch, K.M.; Vyas, B.A.; Shah, D.O. Effect of surfactant chain length on drug release kinetics from microemulsion-laden contact lenses. Int. J. Pharm. 2017, 524, 193-204. [CrossRef]

54. Varshney, M.; Morey, T.E.; Shah, D.O.; Flint, J.A.; Moudgil, B.M.; Seubert, C.N.; Dennis, D.M. Pluronic Microemulsions as Nanoreservoirs for Extraction of Bupivacaine from Normal Saline. J. Am. Chem. Soc. 2004, 126, 5108-5112. [CrossRef]

55. Zhao, Y.; Truhlar, D.G. The M06 suite of density functionals for main group thermochemistry, thermochemical kinetics, noncovalent interactions, excited states, and transition elements: Two new functionals and systematic testing of four M06-class functionals and 12 other functionals. Theor. Chem. Accounts 2008, 120, 215-241. [CrossRef]

56. Frisch, M.J.; Trucks, G.W.; Schlegel, H.B.; Scuseria, G.E.; Robb, M.A.; Cheeseman, J.R.; Montgomery, J.A., Jr.; Vreven, T.K.; Kudin, K.N.; Burant, J.C.; et al. Gaussian 03, Revision C. 02; Gaussian, Inc.: Wallingford, CT, USA, 2004.

57. Miertuš, S.; Scrocco, E.; Tomasi, J. Electrostatic interaction of a solute with a continuum. A direct utilizaion of AB initio molecular potentials for the prevision of solvent effects. Chem. Phys. 1981, 55, 117-129. [CrossRef]

58. Mennucci, B. Polarizable continuum model. Wiley Interdiscip. Rev. Comput. Mol. Sci. 2012, 2, 10.1002. [CrossRef]

59. Boys, S.; Bernardi, F. The calculation of small molecular interactions by the differences of separate total energies. Some procedures with reduced errors. Mol. Phys. 1970, 19, 553-566. [CrossRef]

60. Alkorta, I.; Rozas, I.; Elguero, J. Isocyanides as hydrogen bond acceptors. Theor. Chem. Accounts 1998, 99, 116-123. [CrossRef]

61. Bader, R. Atoms in Molecules; Oxford University Press Inc.: New York, NY, USA, 1990.

62. Zaboli, M.; Raissi, H. A combined molecular dynamics simulation and quantum mechanics study on mercaptopurine interaction with the cucurbit [6,7] urils: Analysis of electronic structure. Spectrochim. Acta Part A Mol. Biomol. Spectrosc. 2018, 188, 647-658. [CrossRef]

63. Biegler-König, F.W.; Bader, R.F.W.; Tang, T.-H. Calculation of the average properties of atoms in molecules. II. J. Comput. Chem. 1982, 3, 317-328. [CrossRef]

64. Glendening, E.; Reed, A.; Carpenter, J.; Weinhold, F. NBO Version 3.1; Gaussian, Inc: Pittsburgh, PA, USA, 1992.

65. Wendt, M.; Weinhold, F. NBOView 1.0; Theoretical Chemistry Institute, University of Wisconsin: Madison, WI, USA, 2001.

66. Brown, W. Dynamic Light Scattering: The Method and Some Applications; Oxford University Press: New York, NY, USA, 1993.

67. Finsy, R. Particle Sizing by Quasi-Elastic Light Scattering. Adv. Colloid Interface Sci. 1994, 52, 79-143. [CrossRef]

68. Rahdar, A.; Almasi-Kashi, M.; Khan, A.M.; Aliahmad, M.; Salimi, A.; Guettari, M.; Kohne, H.E. Effect of ion exchange in NaAOT surfactant on droplet size and location of dye within Rhodamine B (RhB)-containing microemulsion at low dye concentration. $J$. Mol. Liquids 2018, 252, 506-513. [CrossRef]

69. Rahdar, A.; Amini, N.; Askari, F.; Susan, M.; Hasan, A.B. Dynamic light scattering and zeta potential measurements: Effective techniques to characterize therapeutic nanoparticles. J. Nanoanal. 2019. [CrossRef]

70. Sargazi, S.; Moudi, M.; Kooshkaki, O.; Mirinejad, S.; Saravani, R. Hydro-alcoholic Extract of Achillea Wilhelmsii C. Koch Reduces the Expression of Cell Death-Associated Genes while Inducing DNA Damage in HeLa Cervical Cancer Cells. Iran. J. Med. Sci. 2020, 45, 359-367.

71. Twentyman, P.R.; Luscombe, M. A study of some variables in a tetrazolium dye (MTT) based assay for cell growth and chemosensitivity. Br. J. Cancer 1987, 56, 279-285. [CrossRef]

72. Chou, T.-C.; Talalay, P. Quantitative analysis of dose-effect relationships: The combined effects of mul-tiple drugs or enzyme inhibitors. Adv. Enzym. Regulat. 1984, 22, 27-55. [CrossRef]

73. Marques, M.; Cordeiro, M.; Marinho, M.; Vian, C.; Vaz, G.; Alves, B.; Jardim, R.; Hort, M.; Dora, C.; Horn, A. Curcumin-loaded nanoemulsion improves haemorrhagic stroke recovery in wistar rats. Brain Res. 2020, 1746, 147007. [CrossRef] [PubMed]

74. Singh, K.; Singh, N.; Chandy, A.; Manigauha, A. In vivo antioxidant and hepatoprotective activity of methanolic extracts of Daucus carota seeds in experimental animals. Asian Pac. J. Trop. Biomed. 2012, 2, 385-388. [CrossRef] 
75. Ohkawa, H.; Ohishi, N.; Yagi, K. Assay for lipid peroxides in animal tissues by thiobarbituric acid reaction. Anal. Biochem. 1979, 95, 351-358. [CrossRef]

76. Góth, L. A simple method for determination of serum catalase activity and revision of reference range. Clin. Chim. Acta 1991, 196, 143-151. [CrossRef]

77. Sun, Y.; Oberley, L.W.; Li, Y. A simple method for clinical assay of superoxide dismutase. Clin. Chem. 1988, 34, 497-500. [CrossRef]

78. Popelier, P. Atoms in Molecules: An. Introduction; Pearson Education: Harlow, UK, 2000; 164p.

79. Koch, U.; Popelier, P.L.A. Characterization of C-H-O Hydrogen Bonds on the Basis of the Charge Density. J. Phys. Chem. 1995, 99, 9747-9754. [CrossRef]

80. Zaboli, M.; Raissi, H.; Moghaddam, N.R.; Farzad, F. Probing the adsorption and release mechanisms of cytarabine anti-cancer drug on/from dopamine functionalized graphene oxide as a highly efficient drug delivery system. J. Mol. Liquids 2020, $301,112458$. [CrossRef]

81. Espinosa, E.; Molins, E. Retrieving interaction potentials from the topology of the electron density dis-tribution: The case of hydrogen bonds. J. Chem. Phys. 2000, 113, 5686-5694. [CrossRef]

82. Ebrahimi, A.K.; Barani, M.; Sheikhshoaie, I. Fabrication of a new superparamagnetic metal-organic framework with core-shell nanocomposite structures: Characterization, biocompatibility, and drug release study. Mater. Sci. Eng. C 2018, 92, 349-355. [CrossRef]

83. Sharma, S.; Ganju, E.; Upmanyu, N.; Jain, P. THERAPEUTIC MICROEMULSION OF CURCUMIN FOR THE MANAGEMENT OF OSTEOARTHRITIS. J. Drug Deliv. Ther. 2018, 8, 341-347. [CrossRef]

84. Chen, Y.C.; Chen, B.H. Preparation of curcuminoid microemulsions fromCurcuma longaL. to enhance inhibition effects on growth of colon cancer cells HT-29. RSC Adv. 2018, 8, 2323-2337. [CrossRef]

85. Pandey, M.; Choudhury, H.; Gunasegaran, T.A.P.; Nathan, S.S.; Md, S.; Gorain, B.; Tripathy, M.; Hussain, Z. Hyaluronic acidmodified betamethasone encapsulated polymeric nanoparticles: Fabrication, characterisation, in vitro release kinetics, and dermal targeting. Drug Deliv. Transl. Res. 2019, 9, 520-533. [CrossRef]

86. Anwer, K.; Mohammad, M.; Ezzeldin, E.; Fatima, F.; Alalaiwe, A.; Iqbal, M. Preparation of sustained release apremilast-loaded PLGA nanoparticles: In vitro characterization and in vivo pharmacokinetic study in rats. Int. J. Nanomed. 2019, 14, 1587-1595. [CrossRef] [PubMed]

87. Vlachou, M.; Kikionis, S.; Siamidi, A.; Tragou, K.; Ioannou, E.; Roussis, V.; Tsotinis, A. Modified In Vitro Release of Melatonin Loaded in Nanofibrous Electrospun Mats Incorporated Into Monolayered and Three-Layered Tablets. J. Pharm. Sci. 2019, 108, 970-976. [CrossRef]

88. Patel, M.B.; Mandal, S.; Rajesh, K.S. Formulation and kinetic modeling of curcumin loaded intranasal mucoadhesive microemulsion. J. Pharm. Bioallied Sci. 2012, 4, 81-83. [CrossRef]

89. Mokhtari, R.B.; Homayouni, T.S.; Baluch, N.; Morgatskaya, E.; Kumar, S.; Das, B.; Yeger, H. Combination therapy in combating cancer. Oncotarget 2017, 8, 38022-38043. [CrossRef]

90. Miodragović, Đ.; Swindell, E.P.; Waxali, Z.S.; Bogachkov, A.; O’Halloran, T.V. Beyond cisplatin: Combi-nation therapy with arsenic trioxide. Inorgan. Chim. Acta 2019, 496, 119030. [CrossRef]

91. Wilmes, A.; Bielow, C.; Ranninger, C.; Bellwon, P.; Aschauer, L.; Limonciel, A.; Chassaigne, H.; Kristl, T.; Aiche, S.; Huber, C.G.; et al. Mechanism of cisplatin proximal tubule toxicity revealed by integrating transcriptomics, proteomics, metabolomics and biokinetics. Toxicol. In Vitro 2015, 30, 117-127. [CrossRef]

92. Palipoch, S.; Punsawad, C. Biochemical and Histological Study of Rat Liver and Kidney Injury Induced by Cisplatin. J. Toxicol. Pathol. 2013, 26, 293-299. [CrossRef] [PubMed]

93. Yen, F.L.; Wu, T.H.; Tzeng, C.W.; Lin, L.T.; Lin, C.C. Curcumin nanoparticles improve the physico-chemical properties of curcumin and effectively enhance its antioxidant and antihepatoma activities. J. Agric. Food Chem. 2010, 58, 7376-7382. [CrossRef]

94. Joung, H.J.; Choi, M.J.; Kim, J.T.; Park, S.H.; Park, H.J.; Shin, G.H. Development of food-grade curcumin nanoemulsion and its potential application to food beverage system: Antioxidant property and in vitro digestion. J. Food Sci. 2016, 81, N745-N753. [CrossRef]

95. Lee, E.J.; Hwang, J.S.; Kang, E.S.; Lee, S.B.; Hur, J.; Lee, W.J.; Choi, M.-J.; Kim, J.T.; Seo, H.G. Nanoemulsions improve the efficacy of turmeric in palmitate- and high fat diet-induced cellular and animal models. Biomed. Pharmacother. 2019, 110, 181-189. [CrossRef] [PubMed]

96. Ishaq, M.; Evans, M.; Ostrikov, K. Effect of atmospheric gas plasmas on cancer cell signaling. Int. J. Cancer 2014, 134, 1517-1528. [CrossRef] [PubMed] 